\title{
Review Article \\ The Potential for Observing African Weather with GNSS Remote Sensing
}

\author{
Olalekan A. Isioye, ${ }^{1,2}$ Ludwig Combrinck, ${ }^{1,2}$ Joel O. Botai, ${ }^{1}$ and Cilence Munghemezulu ${ }^{1,2}$ \\ ${ }^{1}$ Department of Geography, Geoinformatics and Meteorology, University of Pretoria, Pretoria 0002, South Africa \\ ${ }^{2}$ Hartebeesthoek Radio Astronomy Observatory (HartRAO), P.O. Box 443, Krugersdorp 1740, South Africa \\ Correspondence should be addressed to Olalekan A. Isioye; u13390742@tuks.co.za
}

Received 1 September 2014; Revised 19 January 2015; Accepted 22 January 2015

Academic Editor: Julio Diaz

Copyright (c) 2015 Olalekan A. Isioye et al. This is an open access article distributed under the Creative Commons Attribution License, which permits unrestricted use, distribution, and reproduction in any medium, provided the original work is properly cited.

When compared to the wide range of atmospheric sensing techniques, global navigation satellite system (GNSS) offers the advantage of operating under all weather conditions, is continuous, with high temporal and spatial resolution and high accuracy, and has long-term stability. The utilisation of GNSS ground networks of continuous stations for operational weather and climate services is already in place in many nations in Europe, Asia, and America under different initiatives and organisations. In Africa, the situation appears to be different. The focus of this paper is to assess the conditions of the existing and anticipated GNSS reference network in the African region for meteorological applications. The technical issues related to the implementation of near-real-time (NRT) GNSS meteorology are also discussed, including the data and network requirements for meteorological and climate applications. We conclude from this study that the African GNSS network is sparse in the north and central regions of the continent, with a dense network in the south and fairly dense network in the west and east regions of the continent. Most stations lack collocated meteorological sensors and other geodetic observing systems as called for by the GCOS Reference Upper Air Network (GRUAN) GNSS Precipitable Water Task Team and the World Meteorological Organization (WMO). Preliminary results of calculated zenith tropospheric delay (ZTD) from the African GNSS indicate spatial variability and diurnal dependence of ZTD. To improve the density and geometry of the existing network, countries are urged to contribute more stations to the African Geodetic Reference Frame (AFREF) program and a collaborative scheme between different organisations maintaining different GNSS stations on the continent is recommended. The benefit of using spaced based GNSS radio occultation (RO) data for atmospheric sounding is highlighted and filling of geographical gaps from the station-based observation network with GNSS RO is also proposed.

\section{Introduction and Background}

Satellite-based remote sensing technologies are an integral part of the work of the United Nations Framework Convention on Climate Change (UNFCCC) through the Global Climate Observing System (GCOS). The mandate of GCOS is to determine what data are needed for the monitoring of climate impacts. To this end, GCOS has identified 44 socalled Essential Climate Variables (ECVs) [1]. According to GCOS, progress in producing the forty-four ECVs has been lethargic to date. Nonetheless, the increasing importance of adaptation in terms of both costs and needs has heightened the interest in space-based operations [2].

Atmospheric water vapour is identified as one of the forty-four ECVs. Atmospheric water vapour is one of the most important components of the atmosphere, since it is the means by which moisture and latent heat are transported to influence weather; furthermore it is a greenhouse gas that plays an essential role in the global hydrological cycle and global climate system [3]. Most meteorological processes (convection, cloud formation, and precipitation) are influenced by the local as well as large-scale variability in atmospheric water vapour. Traditional methods of collecting data on atmospheric water vapour do not offer the spatial and temporal resolution necessary for in-depth studies of weather and climate [4]. A better understanding of climate and weather patterns requires data sets that are more comprehensive.

Global navigation satellite systems (GNSS) through a concept referred to as "GNSS meteorology" are a contender 
for providing the water vapour knowledge that atmospheric scientists have been seeking. GNSS receivers/antennas do not require continual calibration as some sensors do for measurement drifts or biases although pressure sensors collocated at GNSS sites occasionally require calibration for instrument drift. Also, large numbers of GNSS measurements can be made temporally and spatially in all weather conditions. Due to the coverage and potential for near-real-time data transmission that GNSS water vapour estimates offer, GNSS could be used to determine the distribution of water vapour over a region of interest and thus help in the identification of potential severe weather activity $[3,5,6]$.

The term GNSS meteorology relates to the utilization of the GNSS radio signals to deliver information about the state of the troposphere. This can be achieved from a satellite platform (GNSS radio occultation meteorology) [7, 8] and ground permanent stations (ground-based GNSS meteorology) $[9,10]$. Continuous observations from GNSS receivers provide an excellent tool for studying the earth's atmosphere. GNSS meteorology has transitioned from research into national and regional networks. The collaboration between the geodetic and meteorological communities has contributed to the meteorological community's understanding of the GNSS representation of water vapour. These and other efforts have resulted in projects and collaboration between GCOS and the International GNSS Service ((IGS) [11-13]) focussed on the operational use of GNSS water vapour estimations [14].

The new technology of GNSS atmospheric remote sensing has several advantages over the conventional water vapour observing system, including global coverage, reliable and stable results, high measurement accuracy, all weather operability, and radio frequencies that can penetrate clouds and dusts [15]. In addition, since the majority of national geodetic institutions and scientific organisations install GNSS receivers in the different regions of the world with dense networks in order to do positioning, mapping, monitor tectonics, and so forth, through collaboration with those, data for zenith total delay (ZTD) estimation for meteorology can be obtained at a low or no cost. GNSS meteorology enables precipitable water vapour (PWV) to be inferred with the same accuracy as conventional meteorological measurements, such as radiosondes, water vapour radiometer (WVR), and microwave profiler (MWP) measurements, to about 1-2 mm PWV accuracy [16]. Comparative and validation results of GNSSZTD/PWV with existing numeric weather prediction (NWP) models such as the European Centre for Medium Weather Forecast (ECMWF) and the National Centre for Environmental Prediction (NCEP) are promising as seen from the works of, for example, Chen et al. [17], Kishore et al. [18], and Koulali et al. [19]. Also, Teke et al. [20], van Malderen et al. [21], and Bock et al. [22] have all reported the performance of GNSS against other geodetic techniques (namely, very long baseline interferometry (VLBI), Doppler Orbitography and Radiopositioning Integrated by Satellite (DORIS), and sun photometers from Aerosol Robotic Network (AERONET)) in the estimation of troposphere parameters with results showing strong correlation among them.
There have been several projects from several organizations on the different continents of the world to derive tropospheric zenith delay measurements from ground-based GNSS, for operational meteorological applications. Examples of such projects in Europe include the COST Action 716 (European Cooperation in the Field of Scientific, Technical Exploitation of Ground-Based GPS for Numerical Weather Prediction Application, 1998-2004) [23], TOUGH (Targeting Optimal Use of GPS Humidity Data in Meteorology, 20032006) [24], and E-GVAP (The EUMETNET GPS Water Vapour Programme, 2004) [25]. E-GVAP network consists of more than 1500 GNSS sites mainly in Europe; recently processing and distribution of global GNSS data have started, since many E-GVAP members run global NWP models. In Africa, the AMMA (African Monsoon Multidisciplinary Analysis Project, 1999-2005) [26, 27] worked on PWV estimation and analysis in the African monsoon region. In North America, the SuomiNet (named to honour meteorological satellite pioneer Verner Suomi) network of receivers provides real-time estimates of water vapour for a global network of receivers from zenith water vapour measurements which are mostly concentrated in the United States (see [4]). Additionally, UCAR's (University Corporation for Atmospheric Research) COSMIC (Constellation Observing System for Meteorology, Ionosphere and Climate) program processes GPS data in PBO (Plate Boundary Observatory) GPS network, CocoNet (Caribbean Network), SuomiNet + NOAA (National Oceanic and Atmospheric Administration), USCG/USACE (United States Coast Guard/US Army Corps of Engineers), DOT (Department of Transportation), and other sites to produce near-real-time (NRT) PWV estimates across North America [28]. The Japanese GEONET (GPS Earth Observation Network) has the largest array of over 1200 GPS stations in the world. It was established for earthquake hazard research and mitigation; scientific applications of the network have been expanded to include meteorology and ionospheric research. Currently, the GEONET contributes to the assimilation of GPS precipitable water vapour data into the JMA (Japan Meteorological Agency) Mesoscale Numerical Prediction Model [29]. Furthermore, two European institutes, Météo France and UK Met Office, use NRT ZTDs in their numerical weather predictions operations today, both reporting a positive impact from the use of ground-based GNSS delay data [30]. Utilizing its capability of water vapour estimation, GNSS has a potential to detect and track extreme changes in weather such as thunderstorms [29]. In addition, NRT GNSS water vapour monitoring for numerical weather prediction services is active in Germany and Austria [31].

All the foregoing discussions demonstrate that GNSS atmospheric remote sensing technology is a key method to improve spatial and temporal sampling of water vapour observation and that GNSS PWV should be a useful source of humidity information for NWP applications. However, there is still no operational GNSS network for GNSS meteorology in Africa, although the application has been investigated at the Hartebeesthoek Radio Astronomy Observatory in terms of South Africa only [32]. Thus, as a practical issue, it is important to build up a network of GNSS stations 
TABLE 1: GRUAN GNSS product requirements (modified after [14]).

\begin{tabular}{|c|c|c|c|c|c|}
\hline Variable & ZTD & ZWD & PWV & PS & $T_{m}$ \\
\hline Measurement range & $1000-3000 \mathrm{~mm}$ & $0-500 \mathrm{~mm}$ & $0-8 \mathrm{~mm}$ & 500-1100 hpa & $20-300 \mathrm{k}$ \\
\hline Accuracy & $4-6 \mathrm{~mm}$ & $6 \mathrm{~mm}$ & $0.1 \mathrm{~mm}$ & $0.01 \mathrm{hpa}$ & $0.2 \mathrm{~K}$ \\
\hline Precision & $4-6 \mathrm{~mm}$ & $6 \mathrm{~mm}$ & $0.1 \mathrm{~mm}$ & $0.5 \mathrm{hpa}$ & $0.1 \mathrm{~K}$ \\
\hline Long-term stability & $0.1-0.4 \mathrm{~mm} / \mathrm{dec}$ & $0.1-0.4 \mathrm{~mm} / \mathrm{dec}$ & $0.01-0.06 \mathrm{Kgm} / \mathrm{dec}$ & $0.1 \mathrm{hpa} / \mathrm{dec}$ & $0.05 \mathrm{~K} / \mathrm{dec}$ \\
\hline Temporal resolution & $1 \mathrm{hr}$ & $1 \mathrm{hr}$ & $1 \mathrm{hr}$ & $1 \mathrm{hr}$ & $1 \mathrm{hr}$ \\
\hline Data latency & 1 month & 1 month & 1 month & 1 month & 1 month \\
\hline
\end{tabular}

TABLE 2: IGS tropospheric products (http://igscb.jpl.nasa.gov/components/prods.html, assessed 20/02/14).

\begin{tabular}{lcccc}
\hline Product & Accuracy & Latency & Updates & Sample interval \\
\hline Final tropospheric zenith path delay & $4 \mathrm{~mm}$ & $<4$ weeks & Weekly & 2 hours \\
Ultrarapid tropospheric zenith path delay & $6 \mathrm{~mm}$ & $2-3$ hours & Every 3 hours & 1 hour \\
\hline
\end{tabular}

across Africa, which can routinely retrieve PWV for weather prediction, atmospheric research, and climate monitoring and prediction. This problem is the main motivation of this review. In view of the different requirements of GNSS meteorology as identified in Isioye [33] and the available GNSS CORS (Continuously Operating Reference Station) network in Africa, there is the need to look into this promising technology and create a working model to accommodate the existing facilities and the general requirement for operational meteorology. These challenges are addressed in this paper.

\section{Operational Requirements and Standards for GNSS Meteorology}

The IGS Troposphere Working Group [34] is currently collaborating with the Global Climate Observing System (GCOS) Reference Upper Air Network (GRUAN). The GRUAN is an international reference-observing network, designed to meet climate requirements and to fill a major void in the current global observing system $[14,35]$. The GRUAN GNSS Precipitable Water (GNSS PW) Task Team was established in 2010 as one of six GRUAN task teams. Ground-based GNSS PW was identified as the utmost priority measurements for GRUAN, and GNSS PW Task Team's goal is to develop explicit guidance on hardware, software, and data management practices to obtain GNSS PW measurements of consistent quality at all GRUAN sites. Both GRUAN and IGS have developed a requirement for GNSS products. A summary of GRUAN GNSS product requirements is presented in Table 1.

As part of the collaboration, expectations are as follows: (a) GRUAN stations should become IGS stations; (b) IGS helps to push GNSS based climate applications according to climatological requirements and process IGS data for climatological applications; (c) further, collaboration to establish central processing and analysis facilities of which IGS is already playing a leading role has been advocated. The IGS currently estimates ZTD and other atmospheric products through its global network. See Table 2 for a summary of IGS atmospheric products.

In addition, the IGS and EUREF [36, 37] have also developed useful guidelines for operational procedure for
GNSS meteorology networks (within the COST716 action user requirements for the use of GNSS in meteorology) [38]. These procedures are summarised under four major component headings as shown in Figure 1. The guidelines from IGS in partnership with GRUAN and EUREF represent the standard for GNSS meteorology at the moment and are in agreement with those specified by WMO.

\section{Status of the African GNSS Network}

Networks of GNSS CORS exist in Africa, which contribute to the IGS and are established and managed by African entities and partners. Densification of IGS networks with its products in Africa is the first step towards the realization of the African Geodetic Reference Frame (AFREF) [39, 40]. Some station requirements and regional issues were discussed in detail by Combrinck and Chin [41, 42]. The densification requires that at least one GNSS CORS be established in every African country. Such networks of CORS are to form the basis of and act as focal points for the establishment of national GNSS networks; and where possible, more than one of such stations can be in a country. It is expected that, on the full realization of AFREF, every country will have a GNSS CORS network with capabilities to fully serve varied national needs and provide other useful products to users, for example, broadcasting differential corrections, and to refine the transformation parameters necessary to relate the national systems to ITRF (International Terrestrial Reference Frame). It is important to note that all IGS stations in Africa are AFREF stations, but not all AFREF stations are IGS stations as well. Furthermore, all AFREF stations are contributing to realize the various national reference frames but not all national GNSS stations are AFREF stations, as is the case already in South Africa, which currently has sixty-six GNSS stations in its national frame but only sixteen stations are AFREF and IGS stations. Figure 2 depicts the distribution of AFREF and IGS stations in Africa. The network is very sparse in the north and central African regions. Currently, there are about thirty-nine IGS stations operating on the African continent; most of the stations are concentrated in the southern part of the continent. 


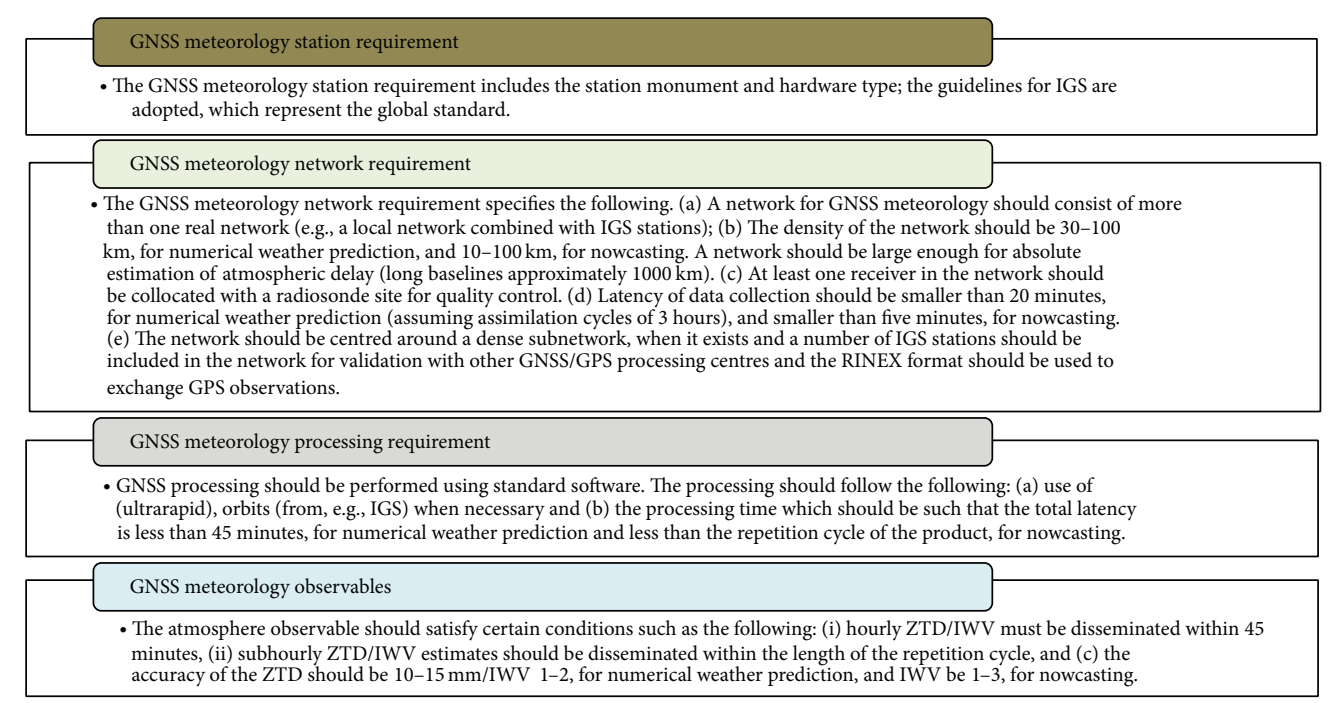

FIGURE 1: Summary of requirements for GNSS meteorology from IGS, GRUAN, and EUREF.

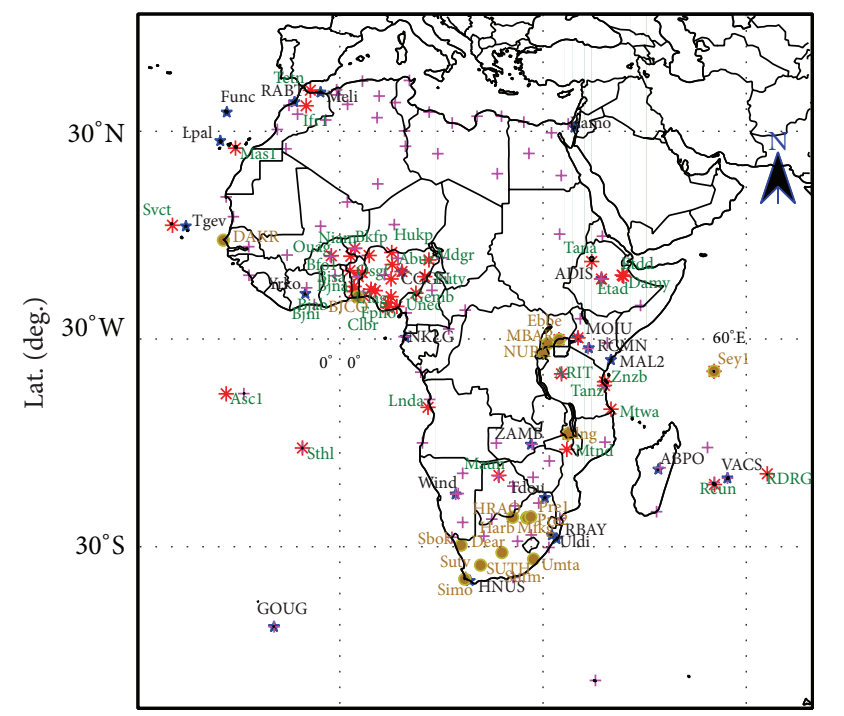

Long. (deg.)

* IGS stations

* AFREF stations

+ Radiosonde stations

- IGS and AFREF stations with collocated met sensors

FIGURE 2: Map depicting the position of IGS and AFREF stations in Africa.

A quick check on the station availability of AFREF stations from the AFREF data web page (http://www.afrefdata .org/) indicates that 81 stations are currently on the scheduled list for daily data logging from individual contributors (countries) in Africa. However, only 25 countries on the continent are currently contributing to the IGS and AFREF. The maximum daily data archive for AFREF in the last three years $(2011,2012$, and 2013) to date $(23 / 02 / 2014)$ stands at 54 stations per day. The reason for inconsistent data streaming from the various stations can obviously be due to communication problems, which has to do with internet connectivity, equipment failure, or in some cases electrical power problems, which is less often.

The site log files and type of data archived by both the IGS and AFREF stations in Africa were inspected for the purpose of this study to ascertain if stations are collocated with meteorological sensors, as it is a requirement by IGS for GNSS meteorology network. It was, however, observed that only a few stations in Africa have met packs collocated with them (see Figure 2). Additionally, not all the GNSS stations collocated with weather sensors that stream meteorological RINEX files to the IGS, as confirmed from SOPAC web data page (http://sopac.ucsd.edu/nearbySites.shtml). Furthermore, only a few GNSS stations in Africa are collocated with radiosondes as required by the GRUAN PW Task Team and IGS. However, there are a few GNSS stations that are within an appreciable distance to the radiosonde sites; this may as well be the situation for weather sensors. Figure 2 further illustrates the distribution of radiosonde stations in Africa as obtained from the Integrated Global Radiosonde Archive (IGRA). Collation of meteorological parameters from the different weather stations for interpolation to the GNSS site as reported in Hadas et al. [43] would be unmanageable in the African context going by instrument variations, political and administrative challenges, cost, and ready access to data.

From the foregoing, the African GNSS network can be seen to have three particularities: (i) sparseness going by the requirement for meteorology, (ii) absence of weather sensors and radiosondes at GNSS sites, and (iii) inconsistency in data streaming from operators due to lack of internet connectivity for data transmission, thereby creating data gaps. The sparseness of the African network implies long interstation distances; this could also lead to a lack of constraints on the orbit solution established by the IGS. Hence, the orbit errors could be more important over Africa than in places with a denser IGS network. These orbit errors would then 
TABLE 3: Comparison of ZTD estimation using different orbit products (the ZTD estimates obtained using IGS final orbits were used as reference to compute the other result) (after [33]).

\begin{tabular}{lccccc}
\hline Orbit type & RMS $(\mathrm{mm})$ & Standard deviation $(\mathrm{mm})$ & Mean difference $(\mathrm{mm})$ & Maximum difference $(\mathrm{mm})$ & Minimum difference $(\mathrm{mm})$ \\
\hline IGS rapid & 0.185 & 0.180 & -0.079 & 0.870 & -1.860 \\
IGS ultrarapid & 1.876 & 1.832 & -0.185 & 29.435 & -19.560 \\
JPL 15 min & 1.549 & 1.511 & -0.197 & 9.435 & -11.560 \\
\hline
\end{tabular}

limit baseline precisions on the long baselines typically found in the African GNSS network. Therefore, the application of GNSS for weather studies will be more limited in Africa; this slight limitation is however not critical as the global orbit adjustments and solutions basically avoid the problem. Thus, the present conditions fall slightly short of international requirements as discussed in the preceding section of this review. The addition of corner cube reflectors on future and current GNSS satellites will ensure Satellite Laser Ranging (SLR) calibration of the satellite orbits; expansion of the SLR network from the southern part of Africa is required to fully exploit benefits that can be had.

For operational weather service, GNSS PWV estimates are required to be in NRT. The NRT data processing involves acquiring and processing of GNSS and ancillary observations to yield signal delay or PWV estimates within a single numerical NWP assimilation cycle. In operational weather prediction, meteorological observations are typically assimilated every 6 hours. With the new generation of meteorological satellite observations provided at intervals of 1 hour 40 minutes, the assimilation delay currently required by the World Meteorological Observation is approximately 2 hours 15 minutes or 3 hours 20 minutes at most. In the case of the Rapid Update Cycle, running operationally for Environmental Prediction, the assimilation delay is approximately 75 minutes [44]. In order to ensure that one cycle of observations is processed before the next satellite orbit is completed, GNSS PWV must be calculated in NRT with a minimum loss of accuracy if they are to be a useable data source in NWP models. To fulfil this objective, the issue of the use of real-time orbits is necessary and must be addressed in the context of the African network. Preliminary investigation into the issue was reported by Isioye [33] in an experiment that utilised GNSS data for three days (GPS week 1578, days 1-3, which correspond to days of years 95-97, 2010) collected from ten IGS stations of the African GNSS network and processed with the IGS final, rapid, and ultrarapid orbits and JPL $15 \mathrm{~min}$ orbits. Table 3 is adapted from Isioye [33] and summarises results of a comparison of the different orbit solutions.

The results obtained using the IGS final orbits were taken as reference and all other results were compared to these. These results clearly demonstrate the potential of GNSS for NRT ZTD estimation and consequently NRT PWV. Further, this confirms that the IGS ultrarapid orbits and the JPL $15 \mathrm{~min}$ orbits could be used for NRT GNSS water vapour estimation, since the RMS of the ZTD estimations is $1.9 \mathrm{~mm}$ and $1.5 \mathrm{~mm}$, respectively. It is expected that estimated PWV will be less than $1 \mathrm{~mm}$, which is quite acceptable for meteorological applications.

\section{Preliminary Results on Monitoring of GNSS ZTD Variability on the African GNSS Network}

4.1. GNSS Data Processing and Tropospheric Product Descriptions. Twelve of the forty-four GNSS stations indicated earlier as IGS stations on the African continent were selected for processing and discussion. Data from the period of 2010-2014 were analysed. The selection of the stations for this discussion was based on the availability and continuity of data at a particular station in relation to other stations in the network. Hence, the temporal connectivity weights $\left(T_{i}\right)$ of the stations in the network were computed. Each station was assigned a temporal connectivity weight equal to

$$
T_{i}=\sum_{k=1}^{N} \frac{1}{n_{k}} \cdot \delta(k)
$$

where $N$ is the total number of days of interest, $n_{k}$ is the number of data for the $k$ th day, and $\delta(k)=1$ if station has data for the $k$ th day and 0 otherwise. Table 4 highlights all IGS stations adopted in the network with associated temporal connectivity weights for the years under review (2010-2014).

The GNSS data analysis has been performed with MIT (Massachusetts Institute of Technology) GAMIT/GLOBK software package (GAMIT version 10.3 [45]). The software has the capability to determine positional information alongside tropospheric parameters, which comprises the ZTD and atmospheric gradient components.

Firstly, to process ZTD from GAMIT, we used final (precise) orbit solution for the satellites from the IGS, adjusting the orbital parameters to avoid day boundary problems. Antenna phase correction is applied following the IGS recommendations [46]. The coordinates of the GNSS stations were heavily constrained to their ITRF 2008 [47] values. Instead of using a single parameter form for the tropospheric parameters, we used a piecewise linear function of ZTD over the session with the number of zenith delay parameters set at thirteen, thus establishing two-hour intervals. The constraint used for zenith delay was 0.2 metres as it is recommended to set it loose enough to encompass any error in wet delay [45]. The variation is defined as parameters of a first-order Gauss Markov process and the zenith variation between points was given as $0.10 \mathrm{~m}$ with $100 \mathrm{hrs}$ of correlation time. The a priori tropospheric delay was calculated according to Saastamoinen [48] based on a standard atmosphere value from the global temperature pressure model (GPT 50). We used the Vienna mapping function [49] and the GNSS data are used down to a cutoff elevation angle of $10^{\circ}$. 
TABLE 4: GNSS sites and associated temporal weights.

\begin{tabular}{|c|c|c|c|c|c|}
\hline Station ID & Country & Latitude (deg.) & Longitude (deg.) & Height $(\mathrm{m})$ & Temporal connectivity weight (2010-2014) \\
\hline ADIS & Ethiopia & 9.0351 & 38.7663 & 2439.1540 & 212.4104 \\
\hline $\mathrm{BJCO}$ & Republic of Benin & 6.3847 & 2.4500 & 30.6000 & 203.1985 \\
\hline CGGN & Nigeria & 10.1231 & 9.1183 & 916.6953 & 67.0596 \\
\hline DAKR & Senegal & 14.7212 & 342.5605 & 51.0000 & 27.3604 \\
\hline HRAO & South Africa & -25.8901 & 27.6870 & 1414.3000 & 232.6287 \\
\hline MBAR & Uganda & -0.6016 & 30.7379 & 1337.6533 & 130.7619 \\
\hline NKLG & Gabon & 0.3539 & 9.6721 & 31.4800 & 214.2571 \\
\hline NURK & Rwanda & -1.9446 & 30.0899 & 1485.0000 & 181.8869 \\
\hline RABT & Morocco & 33.9981 & 353.1457 & 90.1000 & 215.7409 \\
\hline SUTH & South Africa & -32.3802 & 20.8105 & 1799.7660 & 227.5124 \\
\hline YKRO & Cote d'Ivoire & 6.8706 & 354.7599 & 270.0000 & 79.9242 \\
\hline ZAMB & Zambia & -15.4255 & 28.3110 & 1324.914 & 98.2366 \\
\hline
\end{tabular}

The calculated ZTD comprises the hydrostatic (ZHD) and wet (ZWD) component of the delay [31] as shown in

$$
\mathrm{ZTD}=\mathrm{ZHD}+\mathrm{ZWD}
$$

The wet component of the ZTD is the foundation for estimation of water vapour content in the atmosphere. The relation between ZWD and the water vapour content in atmosphere is expressed by IWV (integrated water vapour) and PWV (precipitable water vapour) reported in, for example, Bevis et al. [10] and Kleijer [50] and is expressed as in

$$
\begin{aligned}
\mathrm{PWV} & =\frac{\mathrm{IWV}}{\rho_{w}}=\frac{\left[\mathrm{ZTD}_{\mathrm{GNSS}}-\mathrm{ZHD}\right]}{10^{-6} R_{w} \rho_{w}\left[k_{2}^{\prime}+\left(k_{3} / T_{m}\right)\right]} \\
& =\Pi\left[\mathrm{ZTD}_{\mathrm{GNSS}}-\mathrm{ZHD}\right]=\Pi \cdot \mathrm{ZWD} .
\end{aligned}
$$

In (3), $\rho_{w}$ is the water density, $R_{w}=461.525 \pm$ $0.003\left[\mathrm{~J} \mathrm{~kg}^{-1} \mathrm{~K}^{-1}\right]$ is the specific gas constant for water vapour, $k_{2}^{\prime}$ and $k_{3}$ are refraction constants, and $T_{m}$ is the weighted mean water vapour temperature of the atmosphere measured in Kelvin. It is operationally required to process GNSS data alongside meteorological parameters (temperature, pressure, and humidity) obtained from weather sensors collocated at the GNSS site in the modelling of ZHD and estimation of water vapour. Therefore, with only $T_{m}$ and local surface pressure, it is possible to reduce ZTD estimates from GNSS processing to PWV as shown in (3).

The weighted mean water vapour temperature of the atmosphere $T_{m}$ of the vertical column of air above the GNSS receiver is thus given as [51]

$$
T_{m}=\frac{\int_{h}^{\infty}(e / T) \cdot Z_{w}^{-1} d h}{\int_{h}^{\infty}\left(e / T^{2}\right) \cdot Z_{w}^{-1} d h}=\frac{\int_{h}^{\infty} \rho_{w} d h}{\int_{h}^{\infty}\left(\rho_{w} / T\right) d h} .
$$

In (4), $e$ is the water vapour pressure, $T$ is the temperature, and $Z_{d}^{-1}$ and $Z_{w}^{-1}$ are the inverse compressibility factors of dry air and water vapour, respectively. Thus, $T_{m}$ can be obtained by integrating the vertical profiles of $e$ and T; the integration is done between the GNSS receiver altitude $h$ and infinity utilising radiosonde profiles or outputs fields of
NWP models. This method is limited by the tempospatial resolution of these data products, which is a barrier for GNSS meteorology and is rarely used in real-time PWV estimation. Bevis et al. [10] proposed a linear regression model for estimating $T_{m}$ based on the relationship between surface temperature and $T_{m}$ and this is widely adopted in many studies, though its accuracy varies across the globe and thus there are many regional/local variants of the model [52]. A more recent product with NRT capability for estimating $T_{m}$ is from ECWMF operational analyses provided by the Technical University of Vienna (information online at http://ggosatm.hg.tuwien.ac.at/DELAY/ETC/TMEAN/).

Importantly, meteorological units installed at or near GNSS sites need to be calibrated occasionally for instrument drift and biases, and also surface pressure observations should be reduced to GNSS antenna height [53]. Reduction of surface pressure to GNSS antenna height is possible with the hypsometric equation as follows [53]:

$$
P_{\mathrm{GNSS}}=P \cdot e^{-(g \cdot \Delta H) /\left(R_{d} T\right)} .
$$

In (5), $P_{\mathrm{GNSS}}$ is the pressure at GNSS antenna height (hpa), $R_{d}=287,053\left[\mathrm{~J} \mathrm{~kg}^{-1} \mathrm{~K}^{-1}\right]$ is the gas constant for dry air, $P$ is the pressure at the height of the pressure sensor (hpa), $\Delta H=H_{\mathrm{GNSS}}-H_{S}$ is height difference in metres, and $T$ is the actual mean temperature of the layer between the GNSS antenna and the meteorological sensor in Kelvin.

The ZHD can be calculated using empirical models such as the Saastamoinen, Hopfield, Berman, Davis, Ifadis, and Askne models, as described in Tuka and El-Mowafy [54]. The Saastamoinen model is the most used in geodetic applications and its accuracy has been widely reported [55]. The Saastamoinen model for zenith hydrostatic delay (ZHD), in metres, is expressed as in

$$
\mathrm{ZHD}=0.002277 \cdot \frac{P}{1-0.00266 \cos (\phi)-0.28 \cdot 10^{-6} h},
$$

where $P$ is the surface pressure in mbar, $\phi$ is latitude in radians, and $h$ is the height of the surface above the ellipsoid (in metres). 
The accuracy of PWV is strongly dependent on the accuracy of ZTD values. That is, nearly all of the error in PWV is introduced during the ZTD estimation [10]. The major sources of error in ZTD are GNSS antenna phase centre offsets (PCOs) and phase centre variations (PCVs) and uncertainties in mapping functions. The PCVs and PCOs can together yield systematic effects from 0.3 to $1 \mathrm{~mm}$ and seasonal effects $<0.1 \mathrm{~mm}$ (maximum amplitude). Similarly, the mapping functions can have systematic effects of 0.1$0.5 \mathrm{~mm}$ and seasonal effects of $0.1-0.5 \mathrm{~mm}$. However, most of these errors are rigorously handled within precise GNSS analysis software.

The accuracy of ZHD is greatly influenced by errors in surface pressure and can be approximated by [56]

$$
\sigma_{\mathrm{ZHD}} \approx 0.002277 \cdot \sigma_{p} .
$$

Thus an error, $\sigma_{p}$, in surface pressure of 1 hpa results in a ZHD error, $\sigma_{\mathrm{ZHD}}$, of $2.6 \mathrm{~mm}$. Similarly, the errors in converting ZWD to PWV are primarily the errors in mean atmospheric temperature $\left(T_{m}\right)$ and are approximated by [57]

$$
\sigma_{\Pi} \approx \frac{1}{1768.72} \cdot \sigma_{T_{m}}
$$

Finally, the accuracy of PWV estimates, according to the law of propagation of errors, can be expressed as in [9]

$$
\sigma_{\mathrm{PWV}}=\sqrt{\left(\mathrm{ZWD} \cdot \sigma_{\Pi}\right)^{2}+\left(\Pi \cdot \sigma_{\mathrm{ZHD}}\right)^{2}+\left(\Pi \cdot \sigma_{\mathrm{ZTD}}\right)^{2}} .
$$

Thus for $\sigma_{\mathrm{ZTD}}$ of $4-10 \mathrm{~mm}, \sigma_{p}$ of $2 \mathrm{hpa}$, and $\sigma_{T_{M}}<$ $2 \mathrm{~K}$, the accuracy of PWV estimate ranges from about 1.1 to $1.9 \mathrm{~mm}$. This clearly indicates the level of accuracy required in estimating ZTD, mean temperature, and pressure in GNSS meteorology.

The second tropospheric parameter estimated alongside the ZTD from GAMIT geodetic software is the atmospheric gradient. The estimation of the atmospheric gradients which are the effect of azimuthal asymmetry in the atmospheric delay is given as [45]

$\mathrm{AG}=\operatorname{Grad}_{(\mathrm{N}-\mathrm{S})} \cdot M_{f} \cdot \cos (\mathrm{AZ})+\operatorname{Grad}_{(\mathrm{E}-\mathrm{W})} \cdot M_{f} \cdot \sin (\mathrm{AZ})$,

where $\cos (\mathrm{AZ})$ and $\sin (\mathrm{AZ})$ are cosine and sine functions of the Azimuth (AZ), and $M_{f}$ is the mapping function for the gradients. The gradient parameters, $\mathrm{Grad}_{(\mathrm{N}-\mathrm{S})}$ and $\operatorname{Grad}_{(\mathrm{E}-\mathrm{W})}$, are given to represent the difference in the NorthSouth and East-West delay at $10^{\circ}$ elevation. When using low elevation angle observations, the azimuth asymmetry of the local troposphere gets more important and must be accounted for. Estimating horizontal tropospheric gradients is a common way to cope with these asymmetries and the station coordinate repeatability may be considerably improved by this measure as shown in Miyazaki et al. [58]. The convention of the GAMIT software is to resolve GNSS gradient components at $10^{\circ}$ of elevation in centimetres, but using mapping functions measurement of gradients can be converted into the zenith direction in millimetres. Usually, values of GAMIT gradients components do not exceed $15 \mathrm{~cm}$.

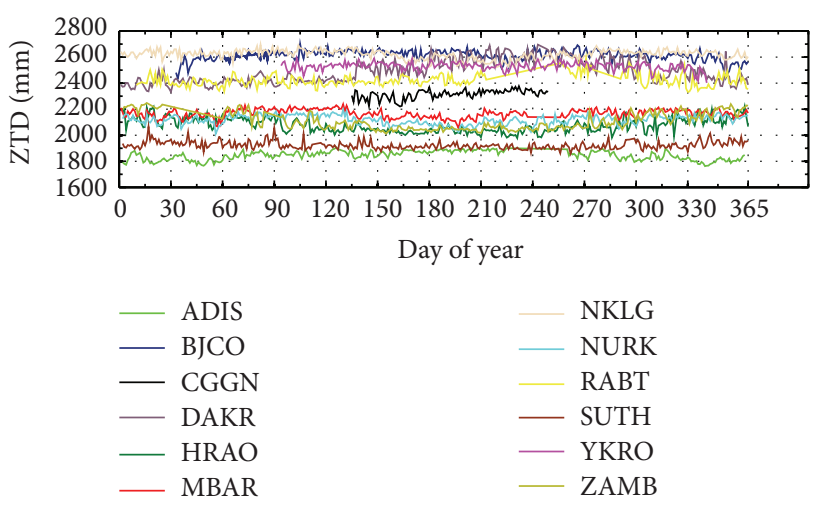

FIGURE 3: Daily variation of ZTD estimates over Africa in 2013 (days 1-365).

In our processing, the a priori constraint for the gradients was set at $0.01 \mathrm{~m}$ in the solution gradient and was thus tightly constrained. The variations for the gradients were defined again as parameters of a first-order Gauss Markov process and the gradient variations between points were given as $0.01 \mathrm{~m}$ with 100 hours of correlation time.

4.2. GNSS ZTD Variability on the African GNSS Network. For the long-term trend analysis in climatic changes, a continuous record for at least thirty years is usually necessary [59]. Climate requires a long time series of observations. The GNSS data from the African network cannot yet provide such a long time series. Nevertheless, the four-and-half-year, twelve times per day database of ZTD over twelve stations in the African GNSS network available for this review provides a unique resource for providing insights into the stability and pattern of distribution of ZTD short-term temporal variations (diurnal variation) of the ZTD distribution above Africa.

In Figure 3, the variation in the daily calculated ZTD is shown at the different sites for days 1-365 in the year 2013. Evident from Figure 3 is the consistency in the ZTDs from season to season. Whilst the general trend in the plot within each monthly seasonality period is similar, there is the need to adequately model the trend taking into consideration conditions at each site and the spatial correlation characteristics of the ZTD values.

From our archived GNSS ZTD data we examine the elevation dependence by first taking the mean of all the measurements at a particular site and then plotting the distribution of mean values versus site elevation as shown in Figure 4. Evidently, it appears that there is strong dependence on elevation, though it is reasonable that ZTD should depend on elevation; after all, it is the water vapour integrated from the observation site to the top of the atmosphere, and if the observation site is higher there will be less atmosphere and hence less water vapour above it. Most sources of water vapour are at the earth's surface. The dependence on elevation is found to be different than that of the major constituents of the dry atmosphere, and it falls off more quickly with elevation than would be expected from total pressure. 


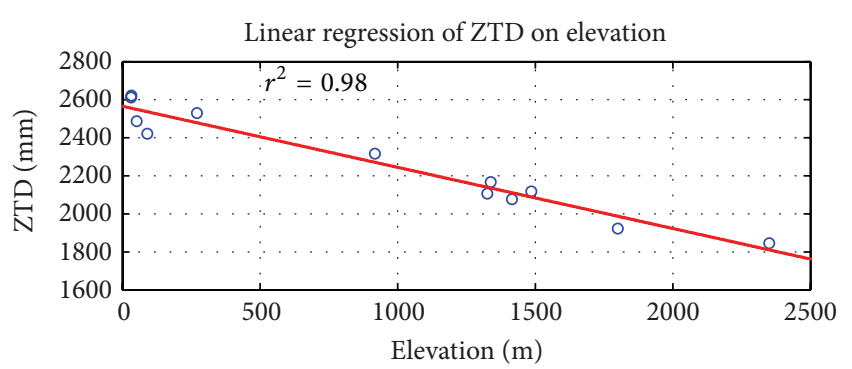

○ Original data

$\longrightarrow$ Linear

FIGURE 4: Plot of GNSS ZTD against station elevation.

To gain insight into the diurnal characteristics of the sites we identified the dominant periods (or frequencies) of the time series at each site using periodograms. A periodogram for each station based on two-hourly data from 2010-2014 is shown in Figure 5 and, also, the average two-hourly data plot over the same period is presented in Figure 6. The periodograms illustrate the relative importance of possible frequency values that might explain the oscillation pattern of the calculated ZTDs. An examination of the plots as presented in Figure 5 reveals that all sites show a diurnal dependence of ZTD when averaged over a long time period. It is also possible that a site may show a diurnal dependence at one time of the year and not during another as a result of seasonal changes.

From the foregoing spatial and temporal variability in GNSS ZTD across Africa is identified, as the different stations tend to exhibit distinct trends in GNSS ZTD variability. Though, further processing, analysis, and modelling of ZTD time series for the purpose of identifying seasonal/annual trends, testing for stationarity (stochastic properties), and homogeneity of ZTD data are needed. The potential of GNSS as a tool for meteorology cannot be overemphasized as the variability identified at the different stations can be correlated with other atmospheric parameters which can serve as indicators for the monitoring and predicting of the weather at such places. Furthermore, GNSS meteorology offers the advantage of ZTD time series being used in NWP models and also ZTD/PWV maps used for nowcasting applications.

\section{Steps to Improve GNSS Meteorology within the African GNSS Network}

The following solutions are offered in view of the peculiarities of the African GNSS network as identified in the preceding section.

\subsection{Densification of GNSS Networks through Collaborative} Initiatives. There are other initiatives in Africa that utilize GNSS data, apart from AFREF, to realize their objectives. This includes the International Space Weather Initiative (ISWI) and the Scintillation Receiver Network (SCINDA) (http:// www.fas.org/spp/military/program/nssrm/initiatives/scinda .htm), which both have a strong interest in populating their observing capability in the equatorial regions of Africa. The AMMA GPS project is primarily a meteorological project aimed at West Africa using GPS as a supporting observing technique $[26,27]$. The Africa Array, currently focusing on seismology, uses GPS as a positioning tool for seismic deployment and exploration surveys (http://www.africaarray .psu.edu/). Some of the Africa Array GNSS stations are contributing to AFREF. Furthermore, African Meridian B-Field Education and Research (AMBER) (http://www.igpp .ucla.edu/public/ekassie/AMBER.html) and African GPS Receivers for Equatorial Electrodynamics Studies (AGREES) (http://www.igpp.ucla.edu/public/ekassie/AGREES.html) all use GNSS data to accomplish their objectives which are specific scientific studies.

Many national agencies in Africa still do not make GNSS data available to the public or to AFREF. In Ethiopia and Malawi there is a dense GNSS network for tectonics monitoring. South Africa has a national network (TRIGNET) of 66 stations. Ghana, Algeria, Egypt, Morocco, and Eritrea have national networks of GNSS stations, but information and data are not yet publicly available to AFREF. In addition, UNAVCO archive data for an ample number of permanent GNSS stations in Africa for different agencies and private organizations. Figure 7 shows the position of different stations in the networks discussed under this section.

Collaboration in terms of data sharing and access between the different initiatives and AFREF operational data centres will go a long way towards improving the density of the current network to enhance meteorological applications.

5.2. Meteorological Parameter Modelling from Global/Regional Weather Models. A few continuous GNSS stations are equipped with meteorological sensors on the African network as shown in Figure 2. Meteorological sensors provide the unique advantage of obtaining on-site meteorological data directly at the continuous GNSS station. The primary disadvantage of GNSS meteorology packs is the lack of vertical temperature profiles necessary for computing the mean atmospheric temperature $\left(T_{m}\right)$ and they often become noisy when left uncalibrated. Radiosondes offer the advantage of providing surface and vertical profiles of temperature, but only a few radiosondes exist close to stations within the existing African GNSS network. Radiosondes are expensive to launch and performance is hindered under bad weather condition. However, there are varieties of reanalysis models from which to obtain such data, which include the following.

(i) The European Centre for Medium-Range Weather Forecasts (ECMWF) 40-year reanalysis (ERA-40) from 1957 to 2002 is based on the ECMWF threedimensional variational assimilation system and makes use of both conventional and satellite observations [60]. The ERA-40 is a grid data set with a spectral resolution of $1.125^{\circ} \times 1.125^{\circ}$, at 60 hybrid vertical levels, at $0000,0600,1200$, and 1800 UTC daily.

(ii) The National Centers for Environmental Prediction/ National Center for Atmospheric Research (NCEP/ NCAR) global reanalysis products (NNR-40) are 

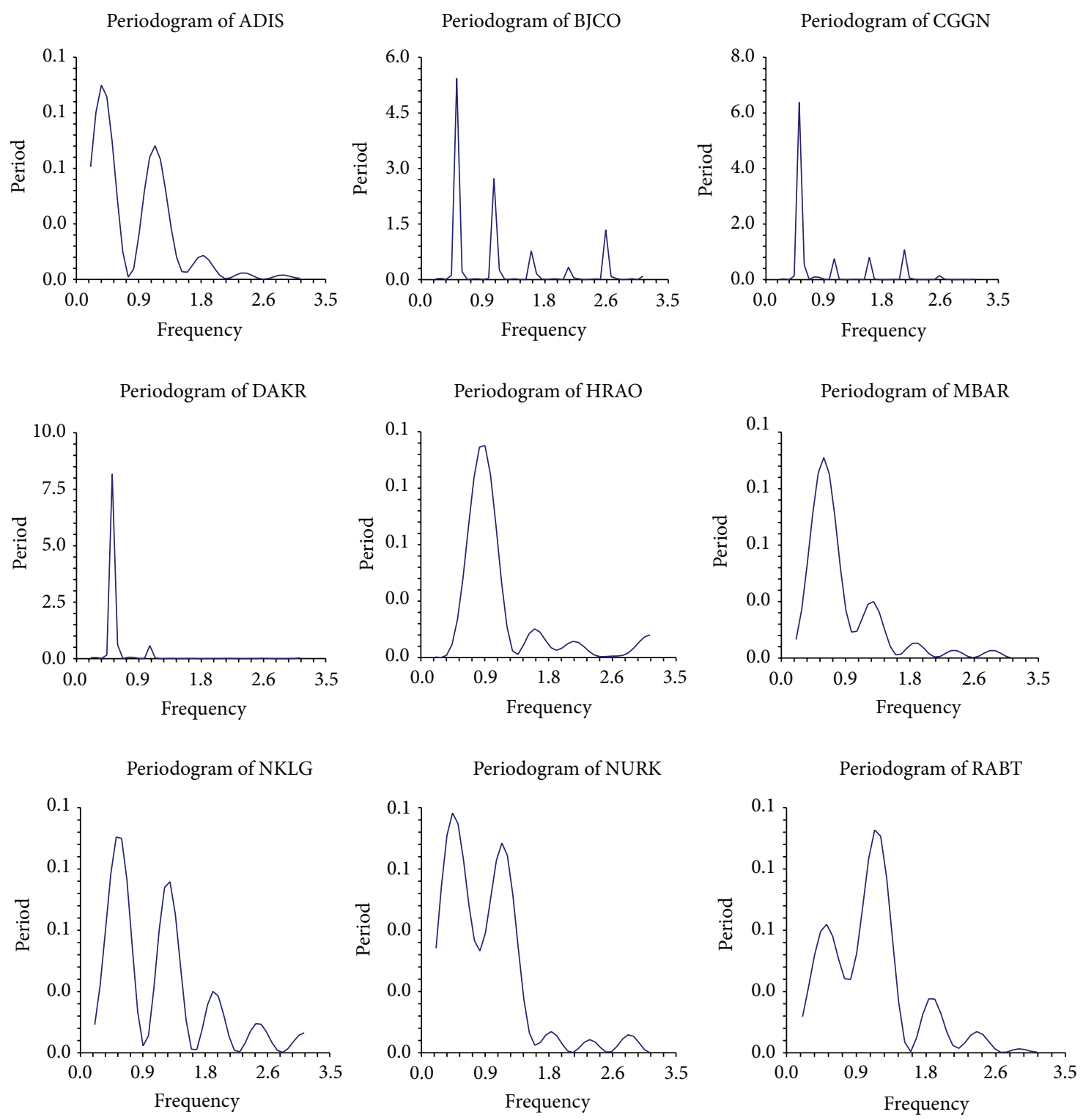

Periodogram of SUTH

Periodogram of YKRO
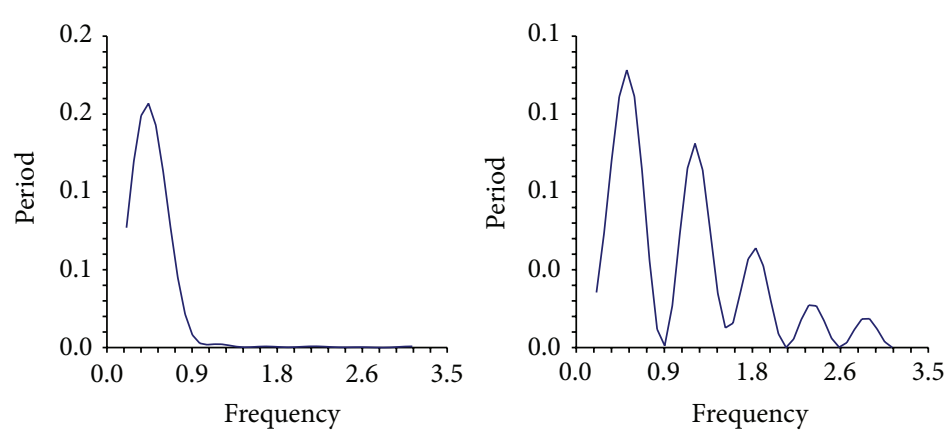

Periodogram of ZAMB

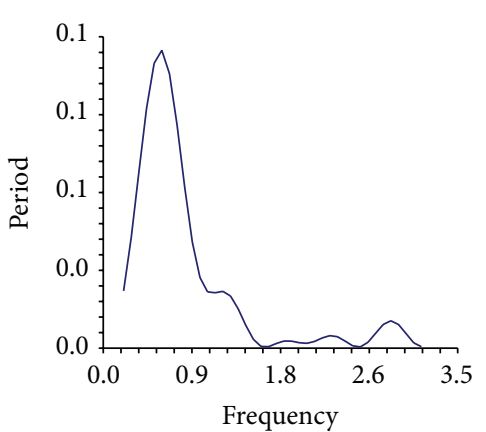

Figure 5: Periodogram graph of ZTD time series. 
Plot of ADIS

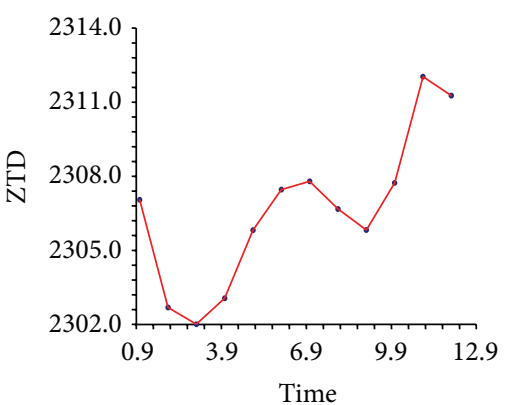

Plot of DAKR

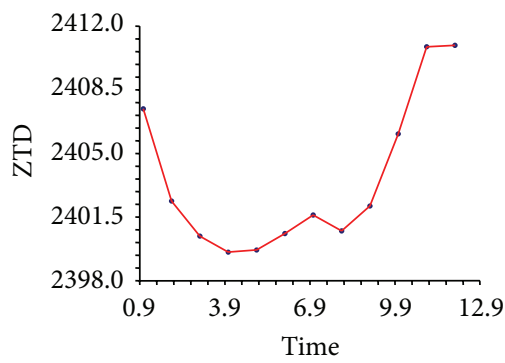

Plot of NKLG

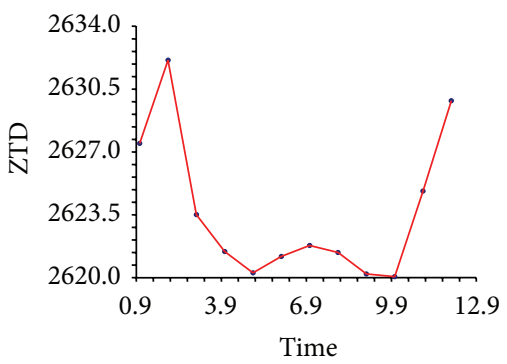

Plot of SUTH

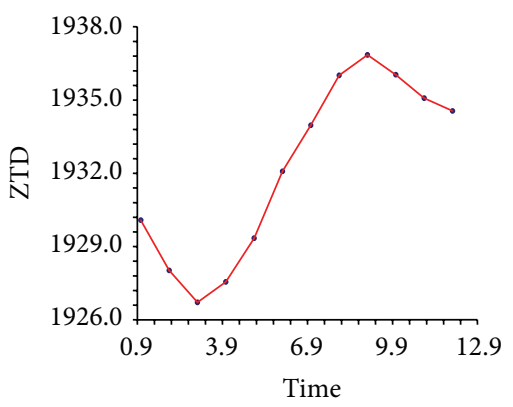

Plot of BJCO

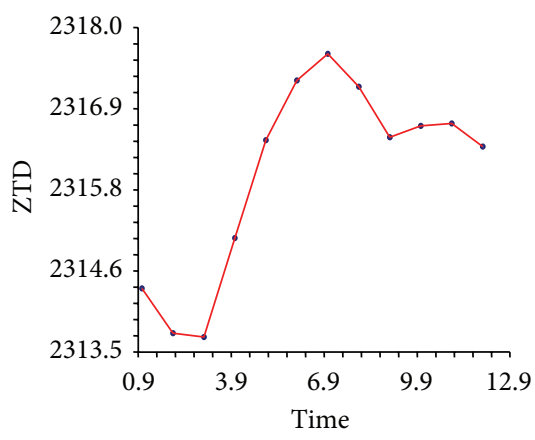

Plot of HRAO

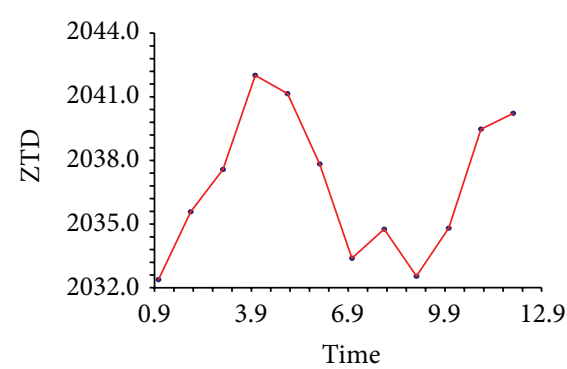

Plot of NURK

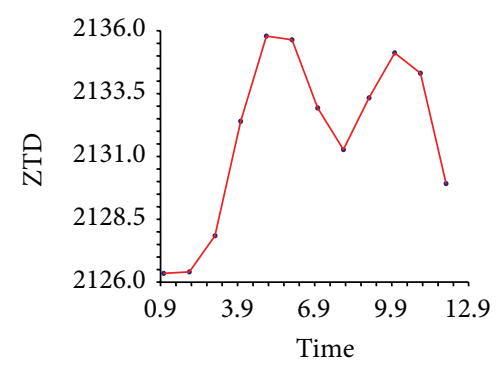

Plot of YKRO

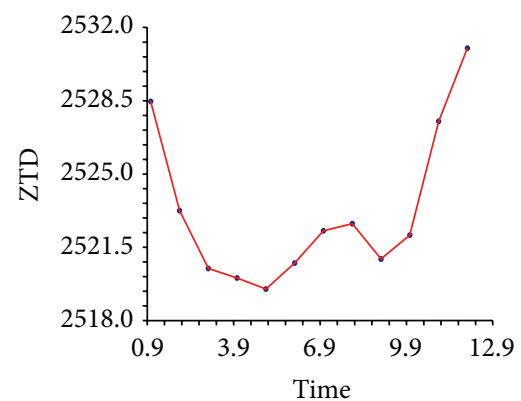

Plot of CGGN

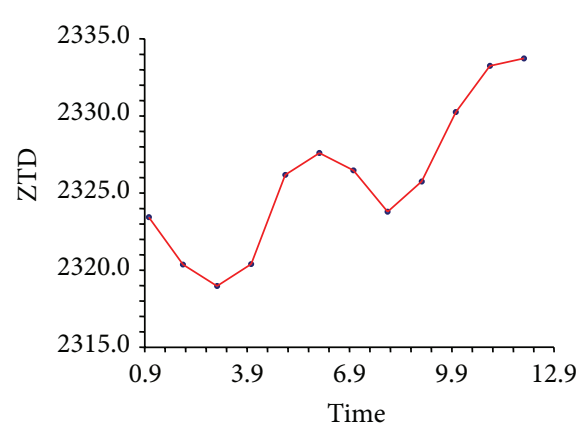

Plot of MBAR

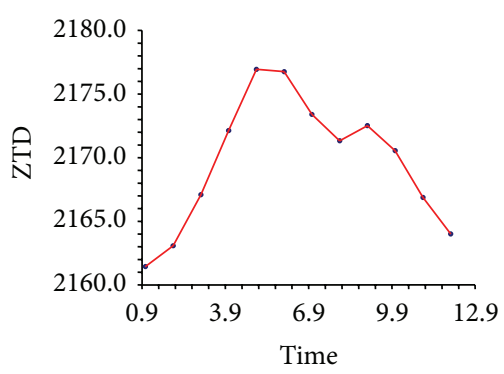

Plot of RABT

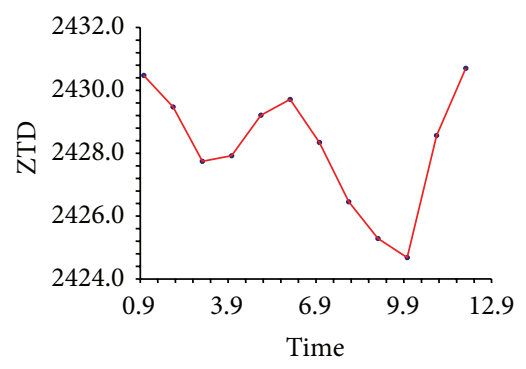

Plot of ZAMB

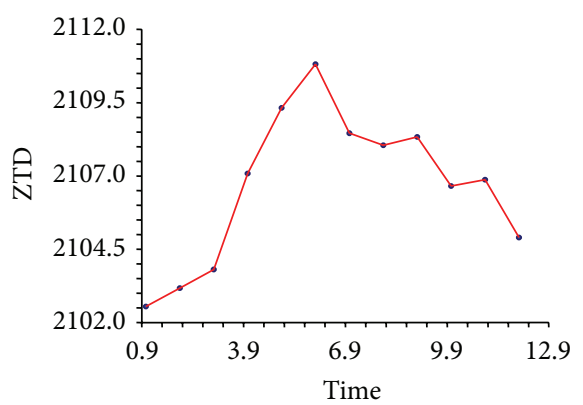

FIGURE 6: Average two-hourly ZTD plots for 2010-2014.

available from 1948 to present. The NNR-40 is again a grid data set having grid size $1.875^{\circ} \times 1.875^{\circ}$, at 28 hybrid vertical levels, available at 0000, 0600, 1200, and 1800 UTC daily [61].

(iii) The ECMWF Interim reanalysis from 1979 to present was only just recently released in 2011, based on the ECMWF4D variational assimilation systems in preparation for the reanalysis to replace ERA-40 [62]. The ERA-Interim is a grid data set with a spectral resolution of $0.75^{\circ} \times 0.75^{\circ}$, having 37 vertical pressure levels. The gridded data products include a large variety of 3-hourly surface parameters, describing 


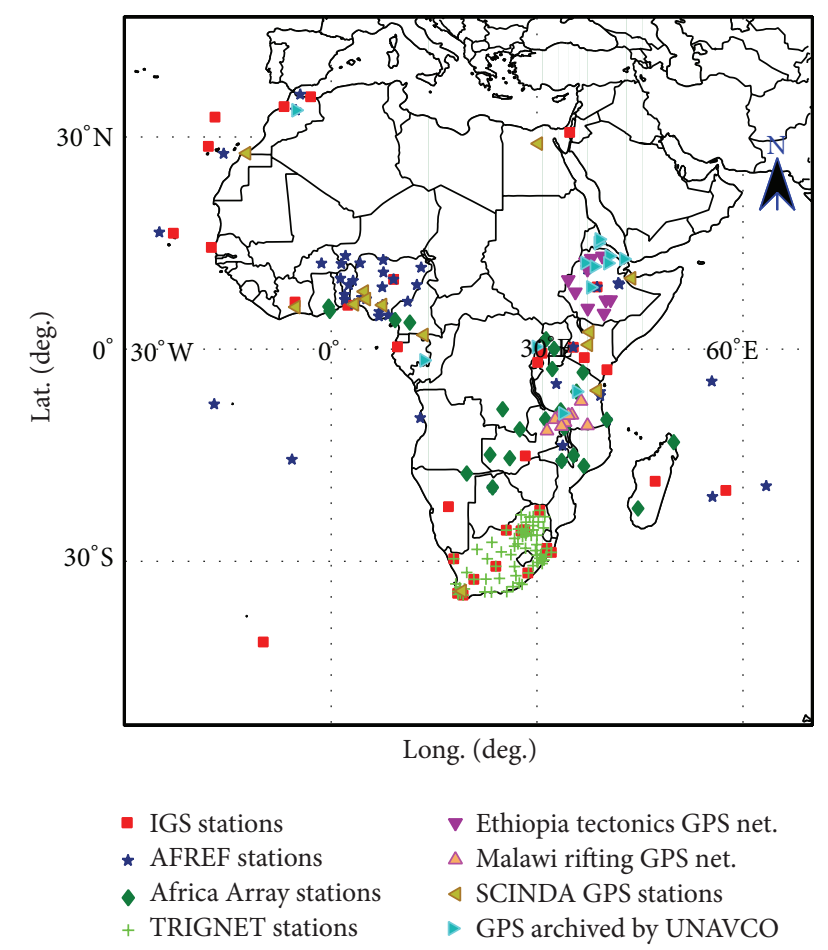

FIGURE 7: Distribution of IGS and AFREF stations and other GNSS stations/networks in Africa.

weather as well as ocean-wave and land-surface conditions, and 6-hourly upper-air parameters covering the troposphere such as temperature and relative humidity. Vertical integrals of atmospheric fluxes, monthly averages for many of the parameters, and other derived fields have also been produced.

The recent release of ERA-Interim provides a clear advantage over ERA-40 [62]. Furthermore, ERA-Interim does not suffer the temporal limitations of ERA-40 thus making it currently the best source for surface pressure and vertical troposphere profiles of temperature and relative humidity necessary for GNSS meteorological calculation. There is a need to assess the applicability of these products in relation to Africa or to develop a regional model for GNSS applications.

5.3. Filling the Gaps with GNSS Radio Occultation (RO). GNSS radio occultation ( $\mathrm{RO}$ ) is a kind of novel method for indirect measurement of temperature, pressure, and water vapour in the stratosphere and the troposphere. The technique is based on using the radio signals continuously broadcasted by the GNSS satellites orbiting the globe at an altitude of approximately 20000 kilometres above the surface from a high precision GNSS receiver mounted on a low earth orbiting (LEO) satellite [18]. A GNSS radio occultation event (ROE) occurs when a GNSS satellite is setting or rising behind the earth's limb as seen by a GNSS receiver aboard a LEO satellite. During an ROE the transmitted signals from the GNSS satellite travelling to the LEO satellite are delayed because of the impacts of the atmosphere and ionosphere $[63,64]$. This delay can be precisely measured and converted to a vertical profile of bending angles and consequently processed to derive a refractivity profile by applying a series of transformation steps [65]. The refractivity is a part of the electron density in the ionosphere and the temperature, pressure, and water vapour in the troposphere. Hence, the GNSS RO technique can offer useful information about the structure and dynamics of the ionosphere, stratosphere, and troposphere.

The RO technique exhibits several beneficial features. First, RO measurements can be obtained under all weather conditions and are available globally. Furthermore, the retrieved atmospheric profiles have high agreements with atmospheric profiles provided by other methods in the upper troposphere and lower stratosphere (UTLS) region, and the data also have high vertical resolution in the same atmospheric regions [66]. Secondly, its measurements are self-calibrated and have long-term stability, which makes RO data highly consistent and can be combined together without the need for intercalibration [67].

Due to these features, the GPS RO technique has become a useful instrument for climate monitoring and has been widely applied in the subject area of the earth's climate and weather. For instance, studies have shown the potential of GNSS RO profiles for characterizing troposphere structures and changes (e.g., [68]) and the obtained results are found to be uniform with other observation data records. The RO data have also been employed for the study of the tropopause (e.g., [69]); atmospheric boundary layer (e.g., [70]); diurnal tides (e.g., [71]); the global gravity wave signatures in the upper troposphere and stratosphere can be obtained from GNSS RO profiles (e.g., [72]). The RO data is also useful for severe weather prediction (e.g., [73]). The RO data have also shown their usefulness in NWP systems. Research indicates that, after the RO data are ingested in the NWP systems, the quality of the weather forecast products is improved (e.g., [74]). In summation to the uses in neutral atmosphere, RO data have been successfully applied to the subject of the ionosphere and also space weather (e.g., [75]).

Many works have shown that the GNSS RO earth atmospheric observational technique can overcome the restrictions of current observing techniques, such as a poor sampling distribution, the low resolution of radiosondes (from land stations, ships, and airplanes), and a low vertical resolution of down-looking satellites [72]. Table 5 contains a comparison of the GNSS RO technique with ground-based GNSS receivers, radiosondes, VLBI, DORIS, and remote sensing methods with regard to atmospheric observations. The outstanding technique for each category is highlighted in italics. The GNSS RO demonstrates significant advantages over the other three techniques.

From the foregoing, the GNSS RO technique is seen as quite promising and stands to fill the existing gaps in atmospheric observation in Africa. It has brought a new impetus for scientists interested in Africa, where traditionally there have been very limited weather observations available. Many countries, such as the USA, Germany, Austria, the Russian Federation, Finland, Italy, Denmark, Argentina, and Brazil, have established experimental GNSS RO meteorology projects and launched a number of LEO experimental 


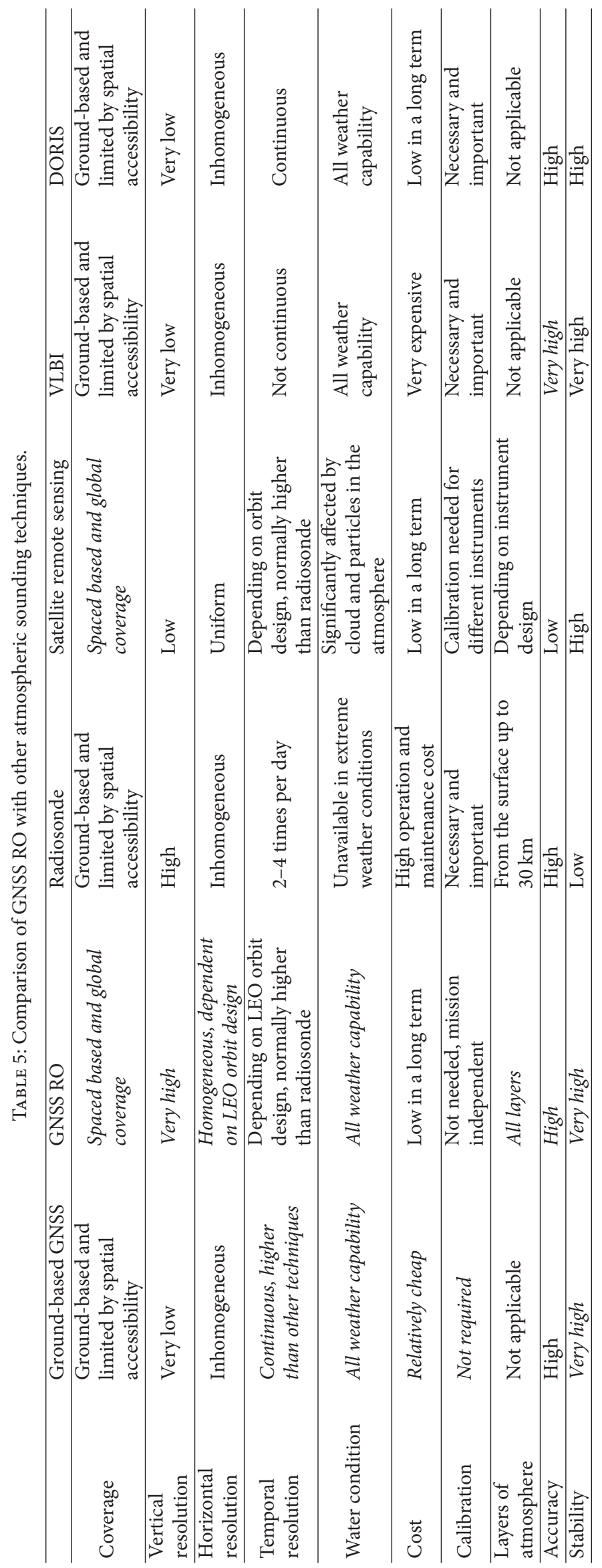


satellites with GNSS RO receivers [76]. New developments of the GNSS RO technique, such as the design of GNSS receivers and the LEO-LEO technique, will offer unprecedented opportunities to obtain a large amount of high-quality and high-resolution observations of the earth's atmosphere [77]. In the near future, with more GNSS RO satellites becoming available, both the weather and climate studies in previously data-sparse areas will be significantly improved. The GNSS RO missions will provide uniform global coverage observations and fill the geographical gaps from the stationbased observation networks. Furthermore, the technique is "mission calibration free" and continuous quality data can be expected over a long term from GNSS RO missions. This is an important improvement for climate studies such as trend analyses.

With the era of GPS modernization and significant expansion of other GNSS, new satellites with new signals have been developed. Within the next decade, about one hundred new GNSS satellites will be launched and thus new signals will be transmitted from them. These satellites will incorporate modernized GPS, GLONASS systems, and the newly designed Galileo. There are also some regional GNSS such as QZSS from Japan, BeiDou from China, and the Indian IRNSS. The next generation RO missions (e.g., FORMOSAT7/COSMIC-2) will be equipped with new GNSS RO receivers, which are designed to receive signals from these new satellites [76]. The horizontal and temporal resolution of RO profiles will be significantly improved due to the increased number of satellites and the improved signal strength and signal spectrum. The quality of the RO technique will also be improved due to the increased number of radio frequencies available for the retrieval process. These new GNSS will utilize different radio frequencies and hence future GNSS $\mathrm{RO}$ missions will take advantage of the different signals to improve the retrieval process for better data quality. The continuous and accurate measurements of the atmospheric profiles with good spatial and temporal resolutions from GNSS RO will be available and new opportunities for better understanding of the earth's atmosphere and ionosphere will follow [78]. Many meteorological and climate related applications, such as numerical weather prediction analysis, climate studies, and ionosphere and space weather conditions, will be passed on with the development of new generation GNSS and LEO satellite programs. Therefore, Africa stands to profit immensely from these future GNSS advancements, as they do not require African funding as in the case of ground-based GNSS receivers, yet coverage will be the same over Africa as everywhere else with minor variations in latitude.

\section{Concluding Remarks}

The theory and practice of ground-based GNSS water vapour estimation have been systematically discussed and demonstrated in this paper. This is an attempt to analytically investigate ground-based GNSS meteorology issues in Africa. Ground-based GNSS meteorology is a very promising application, which could significantly improve numerical weather and storm predictions. Furthermore, it is of great benefit in climate applications. The application of GNSS meteorology has the benefit of being a more economical and efficient approach. It can be unattended for a long period of time with high reliability and with low telemetry data transmission cost. The approach also has a high temporal and spatial resolution when compared with conventional weather balloons. Notwithstanding the scientific and societal applications of GNSS meteorology, most GNSS sites and networks on the African continent as identified in this study do not meet the standards required by the IGS, GRUAN, and the WMO. South Africa is performing pretty well as a number of GNSS stations in the country have meteorological sensors collocated with them; the compactness of the GNSS network in South Africa appears to be well enough for GNSS meteorology, though more effort is still required. In particular, the Hartebeesthoek Radio Astronomy Observatory (HartRAO) in South Africa appears to be the only supersite that collocates other earth observation systems (seismometer, accelerometer, and gravimeter) with GNSS stations (HRAO) and other space geodetic techniques, that is, VLBI, DORIS, WVR, and Satellite Laser Ranging (SLR). However, hope is not lost for other African countries going by the different challenges that are unique for the individual countries, as solutions were proffered in this review. Opportunities such as the African VLBI Network (AVN) [79] can be exploited for synergistic collocations where GNSS and other geodetic as well as geophysical equipment can be collocated. It is suggested that regional/global meteorological model (i.e., NCEP/NCAR and ERA reanalysis) can be investigated for their accuracy on the continent and a suitable interpolation algorithm needs to be developed to enable interpolation from such meteorological models to GNSS observation stations owing to the fact that there are no meteorological sensors installed at most GNSS sites in Africa. Finally, as a step towards attaining an operational GNSS service on the African GNSS network, there is a need for clear policies on data sharing and collaboration among the different organisations that operate GNSS stations on the continent; the idea of collaboration is to add significant extra value to these existing infrastructures. Other potential applications and other techniques of GNSS measurements to meteorology should be explored, that is, GNSS-RO.

\section{Conflict of Interests}

The authors declare that there is no conflict of interests regarding the publication of this paper.

\section{Acknowledgments}

This study was supported by the University of Pretoria Ph.D. research support grant to the first author. The authors are grateful to the numerous reviewers for the constructive comments that helped to improve the paper.

\section{References}

[1] P. Mason, "A review of the 2010 update of the implementation plan for the global observing system for climate in 
support of the UNFCCC,' in Proceedings of the GCOS Steering Committee-Eighteenth Session (GCOS SC '10), Document 13, July 2010.

[2] M. Alessi and C. Egenhofer, Space Observation Systems: An Underused Asset in EU and Global Climate Change Policy, Report of the Centre for European Policy Studies (CEPS), 2011, http://www.ceps.eu/.

[3] S. Boutiouta and A. Lahcene, "Preliminary study of GNSS meteorology techniques in Algeria," International Journal of Remote Sensing, vol. 34, no. 14, pp. 5105-5118, 2013.

[4] R. H. Ware, D. W. Fulker, S. A. Stein et al., "Suominet: a real-time national GPS network for atmospheric research and education," Bulletin of the American Meteorological Society, vol. 81, no. 4, pp. 677-694, 2000.

[5] S. Jin, G. P. Feng, and S. Gleason, "Remote sensing using GNSS signals: current status and future directions," Advances in Space Research, vol. 47, no. 10, pp. 1645-1653, 2011.

[6] A. Karabatić, R. Weber, and T. Haiden, "Near real-time estimation of tropospheric water vapour content from ground based GNSS data and its potential contribution to weather nowcasting in Austria," Advances in Space Research, vol. 47, no. 10, pp. 1691-1703, 2011.

[7] R. A. Anthes, P. A. Bernhardt, Y. Chen et al., "The COSMIC/ Formosat-3 mission: early results," Bulletin of the American Meteorological Society, vol. 89, no. 3, pp. 313-333, 2008.

[8] J. Wickert, G. Michalak, T. Schmidt et al., "GPS radio occultation: results from CHAMP. GRACE and FORMOSAT3/COSMIC," Terrestrial, Atmospheric and Oceanic Sciences, vol. 20, no. 1, pp. 35-50, 2009.

[9] M. Bevis, S. Businger, T. A. Herring, C. Rocken, R. A. Anthes, and R. H. Ware, "GPS meteorology: remote sensing of atmospheric water vapor using the global positioning system," Journal of Geophysical Research, vol. 97, no. 14, pp. 15787-15801, 1992.

[10] M. Bevis, S. Businger, S. Chiswell et al., "GPS meteorology: mapping zenith wet delays onto precipitable water," Journal of Applied Meteorology, vol. 33, no. 3, pp. 379-386, 1994.

[11] J. Kouba, "IGS analysis activities," IGS Annual Report, IGS Central Bureau, Jet Propulsion Laboratory, Pasadena, Calif, USA, 1998.

[12] R. Weber, J. Ray, and J. Kouba, "Review of IGS analysis products," in Proceedings of the IGS Network, Data and Analysis Center Workshop, Ottawa, Canada, April 2002, http://igscb.jpl.nasa.gov/overview/pubs/ottawa_ws.html.

[13] J. M. Dow, R. E. Neilan, and C. Rizos, "The international GNSS service in a changing landscape of Global Navigation Satellite Systems," Journal of Geodesy, vol. 83, no. 3-4, pp. 191-198, 2009.

[14] J. Wickert, K. Rannat, J. Wang et al., "GRUAN GNSS precipitable water task team," in Proceedings of the IGS Workshop, Olsztyn, Poland, 2012.

[15] J. L. Awange and E. W. Grafarend, Solving Algebraic Computational Problems in Geodesy and Geoinformatics, Springer, Berlin, Germany, 2005.

[16] J. Bosy, W. Rohm, A. Borkowski, K. Kroszczynski, and M. Figurski, "Integration and verification of meteorological observations and NWP model data for the local GNSS tomography," Atmospheric Research, vol. 96, no. 4, pp. 522-530, 2010.

[17] Q. Chen, S. Song, S. Heise, Y.-A. Liou, W. Zhu, and J. Zhao, "Assessment of ZTD derived from ECMWF/NCEP data with GPS ZTD over China," GPS Solutions, vol. 15, no. 4, pp. 415-425, 2011.
[18] P. Kishore, M. Venkat Ratnam, S. P. Namboothiri et al., "Global $\left(50^{\circ} \mathrm{S}-50^{\circ} \mathrm{N}\right)$ distribution of water vapor observed by COSMIC GPS RO: comparison with GPS radiosonde, NCEP, ERAInterim, and JRA-25 reanalysis data sets," Journal of Atmospheric and Solar-Terrestrial Physics, vol. 73, no. 13, pp. 1849-1860, 2011.

[19] A. Koulali, D. Ouazar, O. Bock, and A. Fadil, "Study of seasonalscale atmospheric water cycle with ground-based GPS receivers, radiosondes and NWP models over Morocco," Atmospheric Research, vol. 104-105, pp. 273-291, 2012.

[20] K. Teke, J. Böhm, T. Nilsson et al., "Multi-technique comparison of troposphere zenith delays and gradients during CONT08," Journal of Geodesy, vol. 85, no. 7, pp. 395-413, 2011.

[21] R. van Malderen, H. Brenot, E. Pottiaux et al., "A multi-site intercomparison of integrated water vapour observations for climate change analysis," Atmospheric Measurement Techniques, vol. 7, no. 8, pp. 2487-2512, 2014.

[22] O. Bock, P. Willis, M. Lacarra, and P. Bosser, "An intercomparison of zenith tropospheric delays derived from DORIS and GPS data," Advances in Space Research, vol. 46, no. 12, pp. 1648-1660, 2010.

[23] H. van der Marel, "COST-716 demonstration project for the near real-time estimation of integrated water vapour from GPS," Physics and Chemistry of the Earth, Parts A/B/C, vol. 29, no. 2-3, pp. 187-199, 2004.

[24] H. Vedel and X.-Y. Huang, "Impact of ground based GPS data on numerical weather prediction," Journal of the Meteorological Society of Japan, vol. 82, no. 1B, pp. 459-472, 2004.

[25] G. V. Bennitt and A. Jupp, "Operational assimilation of GPS zenith total delay observations into the met office numerical weather prediction models," Monthly Weather Review, vol. 140, no. 8, pp. 2706-2719, 2012.

[26] O. Bock and M. Nuret, "Verification of NWP model analyses and radiosonde humidity data with GPS precipitable water vapor estimates during AMMA," Weather and Forecasting, vol. 24, no. 4, pp. 1085-1101, 2009.

[27] A. Walpersdorf, M.-N. Bouin, O. Bock, and E. Doerflinger, "Assessment of GPS data for meteorological applications over Africa: study of error sources and analysis of positioning accuracy," Journal of Atmospheric and Solar-Terrestrial Physics, vol. 69, no. 12, pp. 1312-1330, 2007.

[28] R. Ware, J. Braun, Y. S. Ha et al., "Real time water vapour sensing with SUOMINET-today and tomorrow," in Proceedings of the International GPS Meteorology Workshop, Tsukuba, Japan, January 2003.

[29] H. Nakamura, K. Koizumi, and N. Mannoji, "Data assimilation of GPS precipitable water vapor into the JMA mesoscale numerical weather prediction model and its impact on rainfall forecasts," Journal of the Meteorological Society of Japan, vol. 82, no. 1, pp. 441-452, 2004.

[30] S. de Haan, "Assimilation of GNSS ZTD and radar radial velocity for the benefit of very-short-range regional weather forecasts," Quarterly Journal of the Royal Meteorological Society, vol. 139, no. 677, pp. 2097-2107, 2013.

[31] J. Bosy, J. Kaplon, W. Rohm, J. Sierny, and T. Hadas, "Near real-time estimation of water vapour in the troposphere using ground GNSS and the meteorological data," Annales Geophysicae, vol. 30, no. 9, pp. 1379-1391, 2012.

[32] A. Z. A. Combrink, W. L. Combrinck, and H. Moraal, "Near real-time detection of atmospheric water vapour using the SADC GPS network," South African Journal of Science, vol. 100, no. 9-10, pp. 436-442, 2004. 
[33] O. A. Isioye, "Towards an operational near real time meteorology on the African GNSS network: challenges and benefits," Nigerian Journal of Scientific Research, vol. 9-10, pp. 90-98, 2011.

[34] S. H. Byun and Y. E. Bar-Sever, "A new type of troposphere zenith path delay product of the international GNSS service," Journal of Geodesy, vol. 83, no. 3-4, pp. 367-373, 2009.

[35] J. Wang, "Global navigation satellite system (GNSS), climate and GRUAN," in Proceedings of the 5th GRUAN ImplementationCoordination Meeting, De Bilt, The Netherlands, February 2013.

[36] J. Ihde, "Developments of the EUREF GNSS services and reference networks," in Proceedings of the 3rd ICG Meeting, Pasadena, Calif, USA, December 2008.

[37] Y. Altiner, C. Bruyninx, J. Ihde, L. Mervant, W. Sohne, and G. Weber, "Development of the EUREF GNSS services and reference networks," in Proceedings of the Workshop on the Application of GNSS, Chisinau, Moldova, May 2010.

[38] S. de Haan, "National/regional operational procedures of GPS water vapour networks and agreed international procedures," Instruments and Observing Methods Report No. 92 WMO/TDNo1340, WMO, 2006.

[39] R. Neilan and R. Wonnacott, Establishing a Continental Reference System in Africa: AFREF, International Council for Science, International Union of Geodesy and Geophysics/International Association of Geodesy, International GPS Service/International Earth Rotation Service and International Society of Photogrammetry and Remote Sensing, 2002.

[40] R. Wonnacott, "AFREF: background and progress towards a unified reference system for Africa," in Proceedings of the FIG Working Week/GSDI-8 Conference, Cairo, Egypt, April 2005, http://www.fig.net/pub/monthly_articles/June_2005/June_ 2005_wonnacott.pdf.

[41] W. L. Combrinck and M. Chin, "IGS stations: station and regional issues," Physics and Chemistry of the Earth, vol. 26, no. 6-8, pp. 539-544, 2001.

[42] W. L. Combrinck and M. Chin, "IGS stations: station and regional issues," in Proceedings of the 1st COST Action 716 Workshop 'Towards Operational GPS Meteorology' and the 2nd Network Workshop of the International GPS Service (IGS '00), H.-P. Plag, S. Barlag, M. Caissey et al., Eds., Oslo, Norway, July 2000.

[43] T. Hadas, J. Kaplon, J. Bosy, J. Sierny, and K. Wilgan, "Near-realtime regional troposphere models for the GNSS precise point positioning technique," Measurement Science and Technology, vol. 24, no. 5, Article ID 055003, 2013.

[44] G. Dick, G. Gendt, and C. Reigber, "First experience with near real-time water vapor estimation in a German GPS network," Journal of Atmospheric and Solar-Terrestrial Physics, vol. 63, no. 12, pp. 1295-1304, 2001.

[45] T. A. Herring, R. W. King, and S. C. McClusky, Introduction to GAMIT/GLOBK, Release 10.3, Department of Earth, Atmospheric and Planetary Sciences, Massachusetts Institute of Technology, Cambridge, Mass, USA, 2006.

[46] G. Gendt and R. Schmid, "Planned changes to IGS antenna calibrations," IGSMAIL-5189, IGS Central Bureau, 2005.

[47] Z. Altamimi, X. Collilieux, and L. Métivier, "ITRF2008: an improved solution of the international terrestrial reference frame," Journal of Geodesy, vol. 85, no. 8, pp. 457-473, 2011.

[48] J. Saastamoinen, "Atmospheric correction for troposphere and stratosphere in radio ranging of satellites," in The Use of Artificial Satellites for Geodesy, S. W. Henriksen, A. Mancini, and B. H. Chovitz, Eds., vol. 15 of Geophysics Monograph Series, pp.
247-252, American Geophysical Union (AGU), AIAA, NOAA, U.S.ATC, Washington, DC, USA, 1972.

[49] J. Boehm, B. Werl, and H. Schuh, “Troposphere mapping functions for GPS and very long baseline interferometry from European centre for medium-range weather forecasts operational analysis data," Journal of Geophysical Research B: Solid Earth, vol. 111, no. 2, Article ID B02406, 2006.

[50] F. Kleijer, Troposphere modelling and filtering for precise GPS levelling [Ph.D. thesis], Department of Mathematical Geodesy, Positioning, Delft University of Technology, Kluyverweg, The Netherlands, 2004.

[51] J. L. Davis, T. A. Herring, I. I. Shapiro, A. E. E. Rogers, and G. Elgered, "Geodesy by interferometry: effects of atmospheric modeling errors on estimates of base line length," Radio Science, vol. 20, no. 6, pp. 1593-1607, 1985.

[52] L. F. Sapucci, "Evaluation of modeling water-vapor-weighted mean tropospheric temperature for GNSS-integrated water vapor estimates in Brazil," Journal of Applied Meteorology and Climatology, vol. 53, no. 3, pp. 715-730, 2014.

[53] S. Vey, R. Dietrich, M. Fritsche, A. Rülke, P. Steigenberger, and M. Rothacher, "On the homogeneity and interpretation of precipitable water time series derived from global GPS observations," Journal of Geophysical Research D: Atmospheres, vol. 114, no. 10, Article ID D10101, 2009.

[54] A. Tuka and A. El-Mowafy, "Performance evaluation of different troposphere delay models and mapping functions," Measurement, vol. 46, no. 2, pp. 928-937, 2013.

[55] J. D. Dodo and T. O. Idowu, "Regional assessment of the GPS tropospheric delay models on the African GNSS network," in Proceedings of the 3rd International Academy of Astronautics African Regional Conference (IAA '09), Abuja, Nigeria, November 2009 .

[56] Z. Bai, Near-real-time GPS sensing of atmospheric water vapour [Ph.D. thesis], Faculty of Built Environment and Engineering, Queensland University of Technology, Brisbane, Australia, 2004.

[57] J. Wang, L. Zhang, and A. Dai, "Global estimates of watervapor-weighted mean temperature of the atmosphere for GPS applications," Journal of Geophysical Research D: Atmospheres, vol. 110, no. 21, Article ID D21101, 2005.

[58] S. Miyazaki, T. Iwabuchi, K. Heki, and I. Naito, "An impact of estimating tropospheric delay gradients on precise positioning in the summer using the Japanese nationwide GPS array," Journal of Geophysical Research, vol. 108, no. 7, article 2335, 2003.

[59] IPCC, "Summary for policymakers," in Climate Change 2007: The Physical Science Basis. Contribution of Working Group I to the Fourth Assessment Report of the Intergovernmental Panel on Climate Change, S. Solomon, D. Qin, M. Manning et al., Eds., Cambridge University Press, Cambridge, UK, 2007.

[60] S. M. Uppala, P. W. Kållberg, A. J. Simmons et al., “The ERA40 re-analysis," Quarterly Journal of the Royal Meteorological Society, vol. 131, no. 612, pp. 2961-3012, 2005.

[61] E. Kalnay, M. Kanamitsu, R. Kistler et al., "The NCEP/NCAR 40-year reanalysis project," Bulletin of the American Meteorological Society, vol. 77, no. 3, pp. 437-471, 1996.

[62] D. P. Dee, S. M. Uppala, A. J. Simmons et al., “The ERA-Interim reanalysis: configuration and performance of the data assimilation system," Quarterly Journal of the Royal Meteorological Society, vol. 137, no. 656, pp. 553-597, 2011.

[63] Y.-A. Liou, A. G. Pavelyev, S.-F. Liu et al., "FORMOSAT3/COSMIC GPS radio occultation mission: preliminary results," 
IEEE Transactions on Geoscience and Remote Sensing, vol. 45, no. 11, pp. 3813-3826, 2007.

[64] Y. Li, A new dynamic approach for statistical optimization of GNSS radio occultation bending angles [Ph.D. thesis], School of Mathematical and Geospatial Sciences, RMIT University, Melbourne, Australia, 2013.

[65] E. R. Kursinski, G. A. Hajj, K. R. Hardy, L. J. Romans, and J. T. Schofield, "Observing tropospheric water vapor by radio occultation using the Global Positioning System," Geophysical Research Letters, vol. 22, no. 17, pp. 2365-2368, 1995.

[66] K. Zhang, E. Fu, D. Silcock, Y. Wang, and Y. Kuleshov, "An investigation of atmospheric temperature profiles in the Australian region using collocated GPS radio occultation and radiosonde data," Atmospheric Measurement Techniques, vol. 4, no. 10, pp. 2087-2092, 2011.

[67] U. Foelsche, B. Scherllin-Pirscher, F. Ladstädter, A. K. Steiner, and G. Kirchengast, "Refractivity and temperature climate records from multiple radio occultation satellites consistent within $0.05 \%$," Atmospheric Measurement Techniques, vol. 4, no. 9, pp. 2007-2018, 2011.

[68] R. A. Anthes, "Exploring Earth's atmosphere with radio occultation: contributions to weather, climate and space weather," Atmospheric Measurement Techniques, vol. 4, no. 6, pp. 10771103, 2011.

[69] X. Xu, J. Luo, and K. Zhang, "An analysis of the structure and variation of the tropopause over China with GPS radio occultation data," The Journal of Navigation, vol. 64, supplement 1, pp. S103-S111, 2011.

[70] S. Sokolovskiy, Y.-H. Kuo, C. Rocken, W. S. Schreiner, D. Hunt, and R. A. Anthes, "Monitoring the atmospheric boundary layer by GPS radio occultation signals recorded in the open-loop mode," Geophysical Research Letters, vol. 33, no. 12, Article ID L12813, 2006.

[71] B. Pirscher, U. Foelsche, M. Borsche, G. Kirchengast, and Y.-H. Kuo, "Analysis of migrating diurnal tides detected in FORMOSAT-3/COSMIC temperature data," Journal of Geophysical Research D: Atmospheres, vol. 115, no. 14, Article ID D14108, 2010.

[72] A. de la Torre, P. Alexander, P. Llamedo, T. Schmidt, and J. Wickert, "Recent advances in gravity wave analysis from long term global GPS radio occultation observations," in New Horizons in Occultation Research: Studies in Atmosphere and Climate, A. Steiner, B. Pirscher, U. Foelsche, and G. Kirchengast, Eds., pp. 153-164, Springer, Berlin, Germany, 2009.

[73] L.-F. Hsiao, D.-S. Chen, Y.-H. Kuo et al., "Application of WRF 3DVAR to operational typhoon prediction in Taiwan: impact of outer loop and partial cycling approaches," Weather and Forecasting, vol. 27, no. 5, pp. 1249-1263, 2012.

[74] L. Cucurull and J. C. Derber, "Operational Implementation of COSMIC observations into NCEP's global data assimilation system," Weather and Forecasting, vol. 23, no. 4, pp. 702-711, 2008.

[75] B. A. Carter, K. Zhang, R. Norman, V. V. Kumar, and S. Kumar, "On the occurrence of equatorial F-region irregularities during solar minimum using radio occultation measurements," Journal of Geophysical Research A: Space Physics, vol. 118, no. 2, pp. 892904, 2013.

[76] E. Fu, An investigation of GNSS radio occultation atmosphere sounding techniques for Australian meteorology [Ph.D. thesis], School of Mathematical and Geospatial Sciences, RMIT University, Melbourne, Australia, 2011.
[77] E. R. Kursinski, D. Ward, A. Otarola et al., "The active temperature, ozone and moisture microwave spectrometer (ATOMMS)," in New Horizons in Occultation Research: Studies in Atmosphere and Climate, A. Steiner, B. Pirscher, U. Foelsche, and G. Kirchengast, Eds., pp. 295-313, Springer, Berlin, Germany, 2009.

[78] R. A. Anthes, C. Rocken, and Y.-H. Kuo, "Applications of COSMIC to meteorology and climate," Terrestrial, Atmospheric and Oceanic Sciences, vol. 11, no. 1, pp. 115-156, 2000.

[79] M. J. Gaylard, M. F. Bietenholz, L. Combrinck et al., "An African VLBI Network of radio telescopes," in Proceedings of SAIP2011, the 56th Annual Conference of the South African Institute of Physics, I. Basson and A. E. Botha, Eds., pp. 473-478, University of South Africa, Pretoria, South Africa, 2011. 

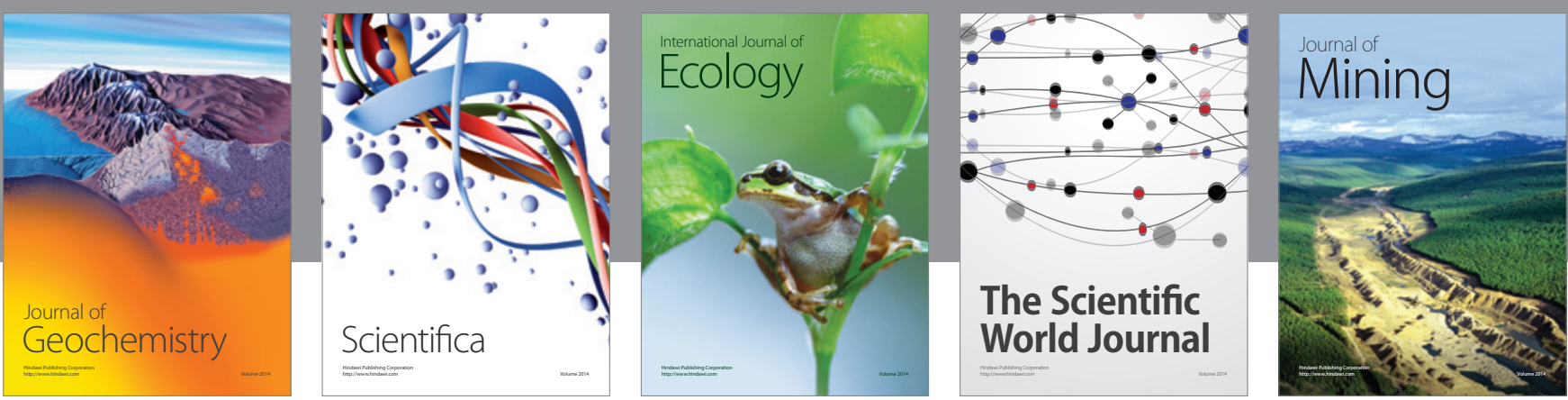

The Scientific World Journal
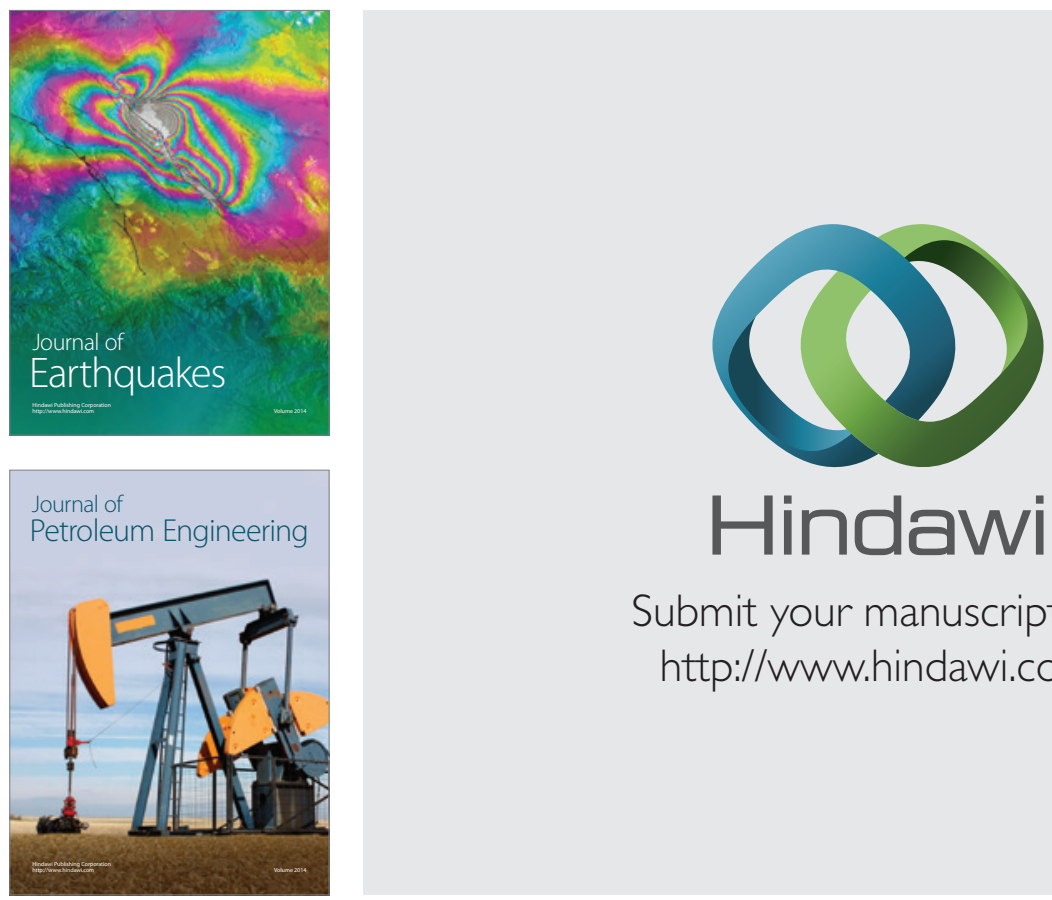

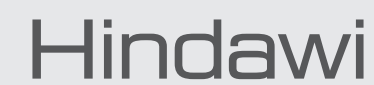

Submit your manuscripts at

http://www.hindawi.com
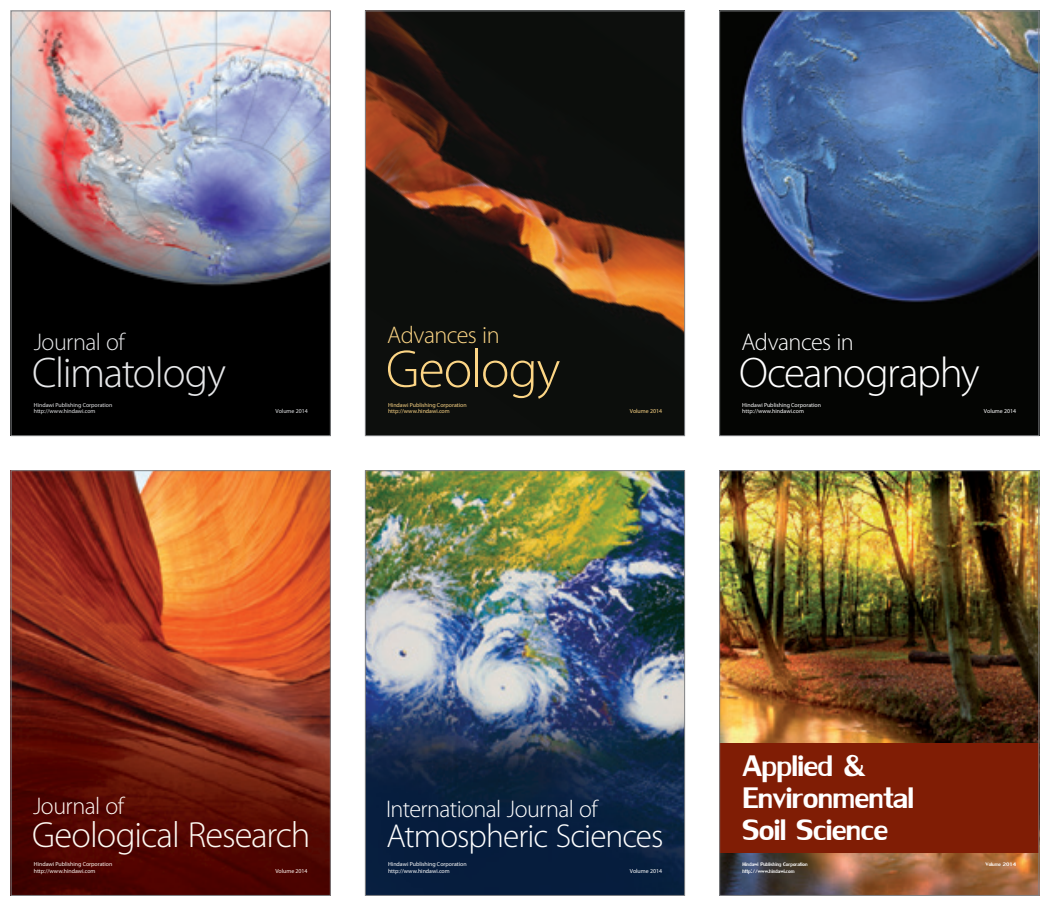
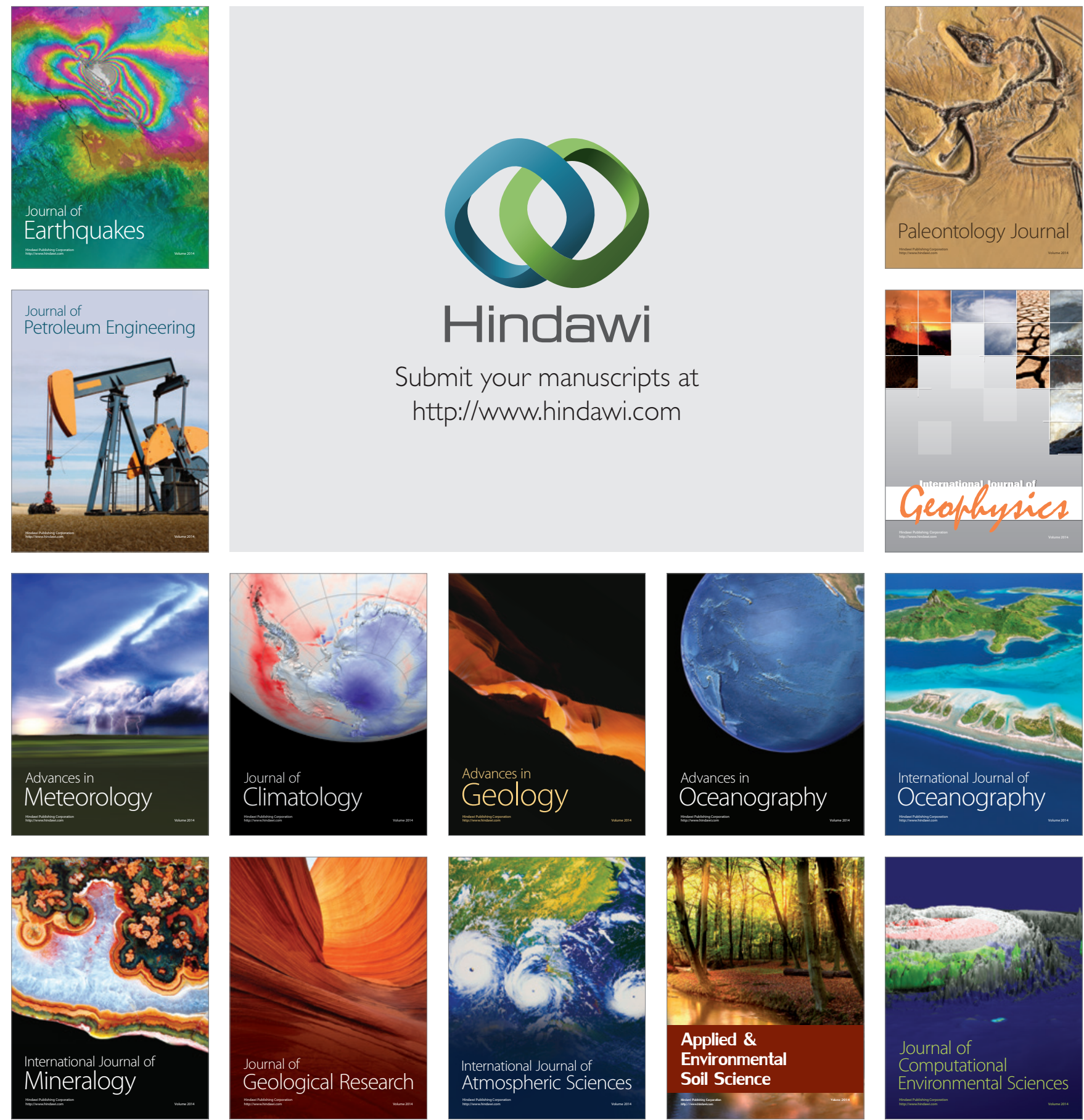